\title{
Simulated enhancement of ENSO-related rainfall variability due to Australian dust
}

\author{
L. D. Rotstayn ${ }^{1}$, M. A. Collier ${ }^{1}$, R. M. Mitchell ${ }^{2}$, Y. Qin ${ }^{2}$, S. K. Campbell ${ }^{2}$, and S. M. Dravitzki ${ }^{1}$ \\ ${ }^{1}$ Centre for Australian Weather and Climate Research, CSIRO Marine and Atmospheric Research, Aspendale, Vic, Australia \\ ${ }^{2}$ Centre for Australian Weather and Climate Research, CSIRO Marine and Atmospheric Research, Canberra, ACT, Australia
}

Received: 20 December 2010 - Published in Atmos. Chem. Phys. Discuss.: 19 January 2011

Revised: 8 June 2011 - Accepted: 30 June 2011 - Published: 12 July 2011

\begin{abstract}
Australian dust emissions are highly episodic, and this may increase the importance of Australian dust as a climate feedback agent. We compare two 160-year coupled atmosphere-ocean simulations of modern-day climate using the CSIRO Mark 3.6 global climate model (GCM). The first run (DUST) includes an interactive treatment of mineral dust and its direct radiative effects. The second run (NODUST) is otherwise identical, but has the Australian dust source set to zero. We focus on the austral spring season, when the correlation between rainfall and the El Niño Southern Oscillation (ENSO) is strongest over Australia. The ENSOrainfall relationship over eastern Australia is stronger in the DUST run: dry (El Niño) years tend to be drier, and wet (La Niña) years wetter. The amplification of ENSO-related rainfall variability over eastern Australia represents an improvement relative to observations. The effect is driven by ENSO-related anomalies in radiative forcing by Australian dust over the south-west Pacific Ocean; these anomalies increase (decrease) surface evaporation in La Niña (El Niño) years. Some of this moisture is advected towards eastern Australia, where increased (decreased) moisture convergence in La Niña (El Niño) years increases the amplitude of ENSOrelated rainfall variability. The modulation of surface evaporation by dust over the south-west Pacific occurs via surface radiative forcing and dust-induced stabilisation of the boundary layer. The results suggest that (1) a realistic treatment of Australian dust may be necessary for accurate simulation of the ENSO-rainfall relationship over Australia, and (2) radiative feedbacks involving dust may be important for understanding natural rainfall variability over Australia.
\end{abstract}

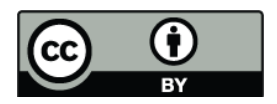

Correspondence to: L. D. Rotstayn (leon.rotstayn@csiro.au)

\section{Introduction}

Mineral dust is both strongly influenced by climate and itself influences climate. Dust aerosols exert substantial direct effects by scattering and absorbing shortwave radiation and absorbing longwave radiation (Satheesh and Moorthy, 2005). In addition to these direct effects, dust affects cloud microphysics and the efficiency of precipitation formation (Wurzler et al., 2000; Rosenfeld et al., 2001). It also provides an important biogeochemical link between terrestrial and marine ecosystems (Ridgwell, 2002). Dust is an important vector for iron supply to the ocean, which subsequently impacts ocean productivity, atmospheric $\mathrm{CO}_{2}$ concentrations, and hence global climate (Mackie et al., 2008).

Regionally, dust can exert large radiative effects, especially on surface shortwave radiation. For example, Haywood et al. (2003) estimated a maximum decrease of short wave radiation at the surface of $209 \mathrm{~W} \mathrm{~m}^{-2}$ during a dust event over the North Atlantic Ocean in September 2000. As a partially absorbing aerosol, dust also tends to increase atmospheric stability and reduce convection (Satheesh and Moorthy, 2005). However, the reality is more complex, because the forcing and response to absorbing aerosols can depend strongly on their relationship to clouds (Liao and Seinfeld, 1998), their optical properties (Miller et al., 2004), altitude (Penner et al., 2003) and the aridity of the environment (Miller et al., 2004).

Climatic conditions strongly influence atmospheric dust concentration, via their effects on dust emission, transport and deposition. For example, transport of African dust across the North Atlantic shows large interannual changes that are highly anticorrelated with rainfall in the SoudanoSahel region (Prospero and Lamb, 2003). Wind erosion of soils is sensitive to vegetation cover and soil moisture, as well as the intrinsic properties of the soil (Gillette and Passi, 1988; Fécan et al., 1999; Webb et al., 2006; Ishizuka et al., 2008). Zender and Kwon (2005) found that, in most

Published by Copernicus Publications on behalf of the European Geosciences Union. 
regions, precipitation and vegetation variations strongly constrain dust anomalies, with dust emission and precipitation being negatively correlated on multiple timescales. However, in some regions dust and precipitation anomalies correlate positively. This can occur where flood-transported sediments increase dust emission during subsequent dry periods (McTainsh et al., 1999).

Numerous studies have shown that aerosols reduce surface insolation, which must be balanced by weaker latent and sensible heat fluxes (e.g., Ramanathan et al., 2001). Absorption of shortwave radiation by aerosols such as dust also causes heating of the lower troposphere and cooling of the surface, which is expected to stabilise the lower atmosphere and reduce convection. This has been shown on regional scales in several modelling studies (Jiang and Feingold, 2006; Grini et al., 2006; Fan et al., 2008; Wendisch et al., 2008). However, modelling also suggests that dustinduced radiative heating can enhance ascent and moisture convergence, leading to increased convection and precipitation in some situations (Stephens et al., 2004; Solmon et al., 2008; Lau et al., 2009; Perlwitz and Miller, 2010).

These effects create the possibility of strong feedbacks between dust and regional climate variations. Saharan dustinduced surface cooling and lower atmospheric heating has been shown to increase atmospheric stability and reduce convection in the tropical Atlantic Ocean; this may explain the strong inverse relationship between inter-annual variations of tropical cyclone activity and Saharan dust outbreaks (e.g., Evan et al., 2006; Sun et al., 2009). Model simulations suggest that direct radiative forcing by increased levels of North African dust can explain up to $30 \%$ of the observed precipitation reduction in the Sahel between wet and dry periods (Yoshioka et al., 2007). Modelling of the 1930s "dust bowl" drought in North America suggests that human-induced land degradation is likely to have contributed to the dust storms and also amplified the drought, in part due to the direct radiative effects of dust (Cook et al., 2009).

Australia is the dominant source of dust in the Southern Hemisphere (Tanaka and Chiba, 2006; Mackie et al., 2008). Satellite retrievals identify the large $\left(1140000 \mathrm{~km}^{2}\right)$ Lake Eyre Basin of central-eastern Australia as the largest dust source in the Southern Hemisphere (Prospero et al., 2002); see also Washington et al. (2003), McTainsh et al. (2007), Bullard et al. (2008) and Mitchell et al. (2010). Compared to the major Northern Hemisphere dust source regions, Australian average dust emissions are relatively low. However, they are very episodic, with periods of high dust activity occurring during drought (McTainsh et al., 2007). Australia's Southern Hemisphere location and the sensitivity of its responses (in both time and space) to rainfall variations may increase the importance of Australian dust as a feedback on climate. Biogeochemical effects of Australian dust have been studied for some time (e.g., Mackie et al., 2008).
To our knowledge, there have been no modelling studies of the direct radiative effects of Australian dust on climate. However, Rotstayn et al. (2010) noted a substantial improvement in the simulation of Australian natural rainfall variability in an updated version of the CSIRO global climate model (GCM), which they tentatively attributed to the inclusion of an interactive dust treatment. They assessed the model's simulation of the leading modes of annual rainfall variability using empirical orthogonal teleconnections (EOTs; van den Dool et al., 2000). Compared to its predecessor (Mark 3.5), the updated model (Mark 3.6) was better able to capture the spatial pattern of the leading rainfall mode, which represents variability due to the El Niño Southern Oscillation (ENSO). In Mark 3.6, the ENSO-related rainfall mode was centred over eastern Australia, in good agreement with observations, whereas in Mark 3.5 it was incorrectly centred over Western Australia.

Based on qualitative arguments, Rotstayn et al. (2010) proposed that by further suppressing convection over eastern Australia during El Niño events (and enhancing it during La Niña events), dust feedbacks may increase the magnitude of rainfall variability there, in tune with the model's ENSO cycle. However, because their updated model included other changes besides the inclusion of an interactive dust scheme, they were unable to state this with confidence. An accurate simulation of this rainfall mode is necessary for modelling the response of Australian rainfall to anthropogenic climate change. The hypothesis also suggests that feedbacks involving dust may be important for understanding natural rainfall variability over Australia. For example, it is possible that there is a positive feedback on drought induced by the recent observed increase in Australian dust (Mitchell et al., 2010).

Here, we investigate the effect of Australian dust on ENSO-related rainfall variability by comparing two coupled ocean-atmosphere simulations with the CSIRO Mark 3.6 GCM (hereafter Mk3.6). The first is an extension of the run described by Rotstayn et al. (2010), with the Australian dust source included. The second run is otherwise identical, but the Australian dust source is set to zero. By comparing two runs which differ on only one respect, it should be possible to isolate the effect of Australian dust.

\section{Model and simulations}

\subsection{Model description}

The CSIRO Mk3.6 GCM is described by Rotstayn et al. (2010). It was developed from the earlier Mk3.5 version (Gordon et al., 2010); for an historical overview see Smith (2007). It is a coupled ocean-atmosphere model with dynamic sea ice, and horizontal resolution of approximately $1.9^{\circ} \times 1.9^{\circ}$ (spectral T63). The atmospheric component has 18 vertical levels. The main differences between Mk3.5 and Mk3.6 are the incorporation of an interactive aerosol 
treatment and an updated radiation scheme in the latter. The aerosol species treated interactively are sulfate, black carbon, organic aerosol, mineral dust and sea salt. All the above aerosol types, except for sea salt, are treated prognostically by the model, so that equations are included for their emission, transformation, transport and removal at each time step. In all, there are 11 prognostic variables in the aerosol scheme: dimethyl sulfide (DMS), sulfur dioxide $\left(\mathrm{SO}_{2}\right)$, sulfate, hydrophobic and hydrophilic forms of black carbon and organic aerosol, and four size bins of mineral dust, with radii ranging from $0.1-1,1-2,2-3$ and $3-6 \mu \mathrm{m}$ respectively. A further two modes of sea salt are diagnosed as a function of wind speed in the marine boundary layer, but are not treated prognostically. Also, the distribution of stratospheric aerosol from volcanic eruptions is prescribed using monthly mean data (extended from Sato et al., 1993). Rotstayn et al. (2007) give further details of the aerosol schemes (including their limitations). The aerosol treatments are supported by an updated radiation scheme that includes aerosol-radiative effects (Grant et al., 1999; Chou and Lee, 2005; Rotstayn et al., 2007). The radiation scheme treats the shortwave effects of all the above aerosol types and the longwave effects of dust and volcanic aerosol. Indirect effects of aerosol on liquidwater clouds depend only on sulfate, carbonaceous aerosol and sea salt (Rotstayn et al., 2010), and it should be noted that indirect effects of dust are not included in the model.

The treatment of mineral dust emission follows Ginoux et al. (2001, 2004). The scheme is based on satellite retrievals from the Total Ozone Monitoring Spectrometer (TOMS), which indicate that most major dust sources correspond to topographic depressions (Prospero et al., 2002). These are typically dry lakes or riverbeds where a sufficiently deep layer of loose alluvial sediment was able to accumulate. Zender et al. (2003) found that assigning enhanced erodibility to topographic minima (as in Ginoux et al., 2001) realistically increases emissions in several regions, including the Lake Eyre basin in central-eastern Australia. The characterisation of the Lake Eyre basin as the major Australian dust source is also broadly consistent with several studies cited in the Introduction. The dust source function depends on the prescribed spatial distribution of soil erodibility for each dust size class and a threshold value of 10 -metre wind speed $\left(V_{10} \mathrm{~m}\right)$. Above this threshold wind speed $V_{\mathrm{t}}$, which is a function of soil moisture, the dust source is proportional to $V_{10 \mathrm{~m}}^{2}\left(V_{10 \mathrm{~m}}-V_{\mathrm{t}}\right)$; see Ginoux et al. (2004).

To account for mesoscale variations that are unresolved on the relatively coarse grid of our GCM, our dust emission scheme includes a parameterization of sub-grid gustiness due to deep convection and boundary-layer free convection, based on Redelsperger et al. (2000). The term related to deep convection is (in $\mathrm{m} \mathrm{s}^{-1}$ )

$V_{\text {deep }}=\left(\frac{19.8 R^{2}}{1.5+R+R^{2}}\right)^{0.4}$ where $R$ is the rainfall rate in $\mathrm{cm}$ per day. The term related to free convection is

$V_{\text {free }}=0.65 w_{*}$

where $w_{*}$ is the free convection velocity (Deardorff, 1970). As noted by Lunt and Valdes (2002), these terms can plausibly be added in quadrature, or linearly, with the latter giving a larger effect. In the current version of our model, the terms are added linearly, so that the effective 10-metre wind speed used in the dust emission scheme is

$V_{10 \mathrm{~m}}=V_{10 \mathrm{~g}}+V_{\text {deep }}+V_{\text {free }}$

where $V_{10 \mathrm{~g}}$ is the grid-resolved 10-metre wind speed.

Transport of dust occurs by advection, vertical turbulent mixing and vertical transport inside deep convective clouds. Vertical advection is handled using a flux-corrected transport scheme (Van Leer, 1977), and horizontal advection is handled via a semi-Lagrangian scheme (McGregor, 1993). The treatment of vertical turbulent mixing is based on stabilitydependent K-theory (Louis, 1979). Under convective conditions, an additional non-local counter-gradient flux is added (Holtslag and Boville, 1993). Convective transport is based on the vertical profiles of the updraft mass flux and compensating subsidence generated by the convection scheme (Gregory and Rowntree, 1990).

Removal of dust from the atmosphere occurs via wet and dry deposition and gravitational settling. Wet deposition is linked to the formation of warm rain and frozen precipitation in the stratiform-cloud and convection schemes (Rotstayn and Lohmann, 2002). The treatment of dry deposition and gravitational settling is described by Ginoux et al. (2001).

The model's dust optical properties were revised by Rotstayn et al. (2010), to improve the shortwave treatment and to include longwave effects, which were previously omitted. The refractive indices used to derive the shortwave optical properties were revised due to mounting evidence from observations that older models tend to overestimate the absorption of shortwave radiation by dust (Myhre et al., 2003; Yu et al., 2004). The revised scheme uses refractive indices based on measurements at Bahrain (Dubovik et al., 2002); these have smaller imaginary components than the old refractive indices, giving less absorptive dust. In the mid-visible band (497.5-692.5 nm), the single scattering albedos (SSAs) for the four dust size bins $(0.1-1,1-2,2-3$ and 3-6 $\mu \mathrm{m})$ are $0.977,0.943,0.915$ and 0.873 respectively. In the global mean, the bulk mid-visible SSA of dust (weighted by optical depth) is 0.961 , confirming that dust is a weakly absorbing aerosol in our model. Due to the variation of SSA with particle radius, SSA tends to be somewhat smaller over major dust source regions $(\sim 0.95)$ and somewhat larger over remote regions ( 0.97), as in Miller et al. (2004) .

Longwave effects of dust were included by tabulating single-scattering properties from OPAC (Optical Properties 
(a) SW dust TOA forcing (global mean $-0.82 \mathrm{~W} / \mathrm{m} 2$ )

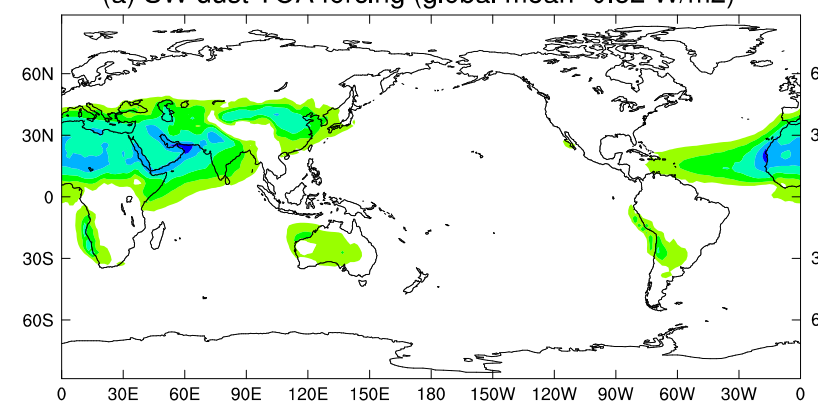

(c) SW dust surface forcing (global mean $-2.19 \mathrm{~W} / \mathrm{m} 2$ )

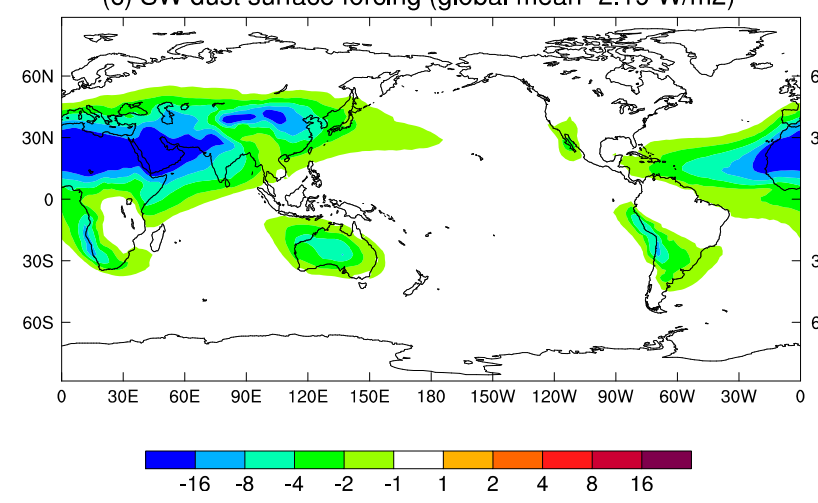

(b) LW dust TOA forcing (global mean $+0.26 \mathrm{~W} / \mathrm{m} 2$ )

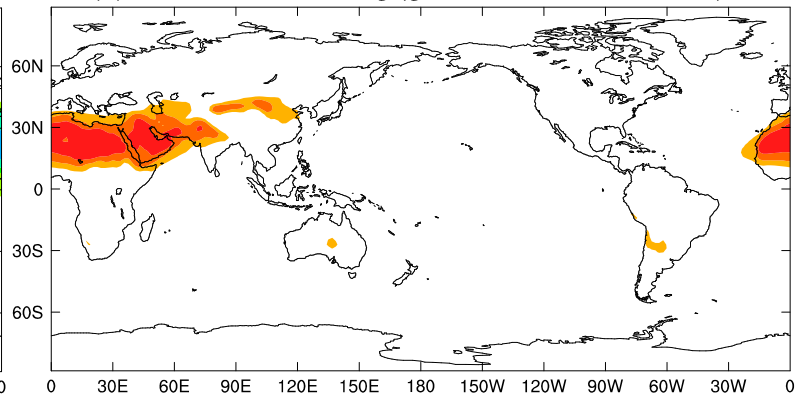

(d) LW dust surface forcing (global mean $+0.91 \mathrm{~W} / \mathrm{m} 2$ )

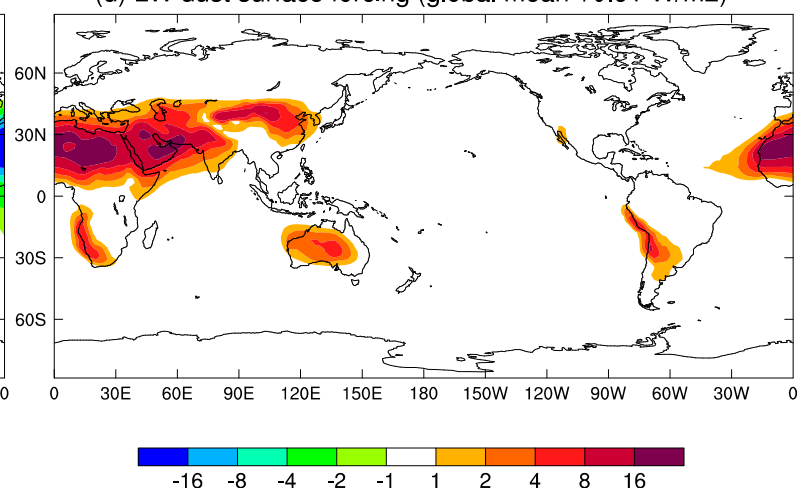

Fig. 1. Annual-mean simulated dust radiative forcing from the DUST run in $\mathrm{W} \mathrm{m}^{-2}$ (a) shortwave at the top of the atmosphere, (b) longwave at the top of the atmosphere, (c) shortwave at the surface, and (d) longwave at the surface.

of Aerosols and Clouds; Hess et al., 1998), using their mineral dust nucleation and accumulation modes to represent the radiation scheme's small and large dust modes respectively.

\subsection{Simulations}

We compare two 160-year coupled atmosphere-ocean simulations with the Mk3.6 GCM. Both simulations have forcing (greenhouse gases, anthropogenic aerosols and ozone) appropriate for the year 2000. The DUST run is a continuation of the 70-year run described by Rotstayn et al. (2010): we extended this run to a total of 240 years. The setup of the NODUST run is identical to that of the DUST run, except that the Australian dust source is set to zero. NODUST was initialised from the end of the above 70-year run, and was also integrated to the end of year 240. We show results from the last 160 years of both simulations, to allow for a 10 -year spinup period in NODUST. Hereafter, we label these as years 1 to 160 , so that year 1 is equivalent to year 81 in the original terminology. To investigate dust-ENSO interactions, we will mainly focus on the Austral spring season, September to November (SON), when the effect of ENSO on Australian rainfall is strongest (McBride and Nicholls, 1983).

The simulation of mean seasonal Australian climate in the earlier 70-year run was evaluated by Rotstayn et al. (2010), who found that in most respects the model performed well.
In particular, calculation of a non-dimensional skill score (the "M-statistic"; Watterson, 1996), using data from all four seasons, confirmed that Mk3.6 gave a better simulation than a majority of GCMs from the Coupled Model Intercomparison Project Phase 3 (CMIP3).

\section{Results}

\subsection{Dust simulation}

The annual-mean global dust load from the DUST run is $35 \mathrm{Tg}$, towards the high end of the range $(8-36 \mathrm{Tg}$ ) found in 16 global models reviewed by Zender et al. (2004). This is likely due to the treatment of sub-grid wind fluctuations in the dust emission scheme (Eq. 3), which contributes to a relatively large global dust emission $\left(3569 \mathrm{Tg} \mathrm{yr}^{-1}\right)$ in the DUST run. This is somewhat larger than the range of 1000 to $3000 \mathrm{Tg}$ that was found to be consistent with observations by Cakmur et al. (2006). In common with other global modelling studies (e.g., Ginoux et al., 2001; Woodward, 2001; Tegen et al., 2002; Zender et al., 2003; Miller et al., 2006; Tanaka and Chiba, 2006; Yoshioka et al., 2007), the dust load in the Northern Hemisphere (29 Tg) is much larger than that in the Southern Hemisphere (6 Tg).

Figure 1 shows the direct radiative forcing of dust at the top of the atmosphere and the surface. We calculated these 
(a) Annual observed dust loading from AATSR

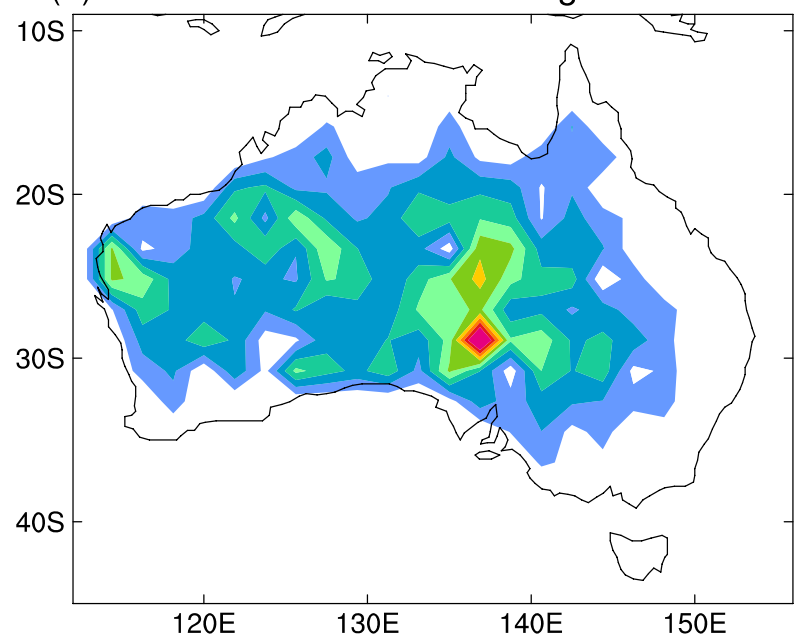

(c) SON observed dust loading from AATSR

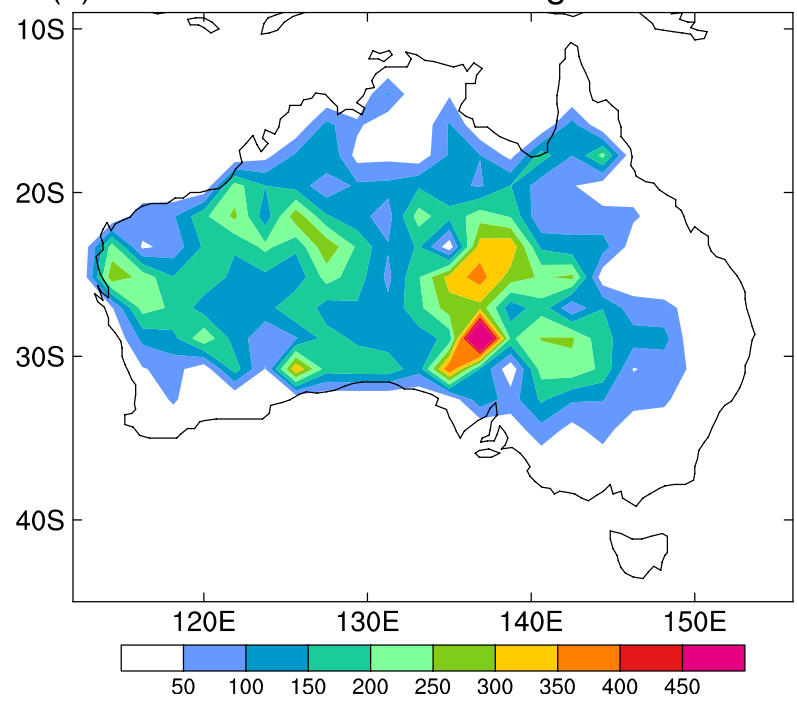

(b) Annual modelled dust loading from Mk3.6

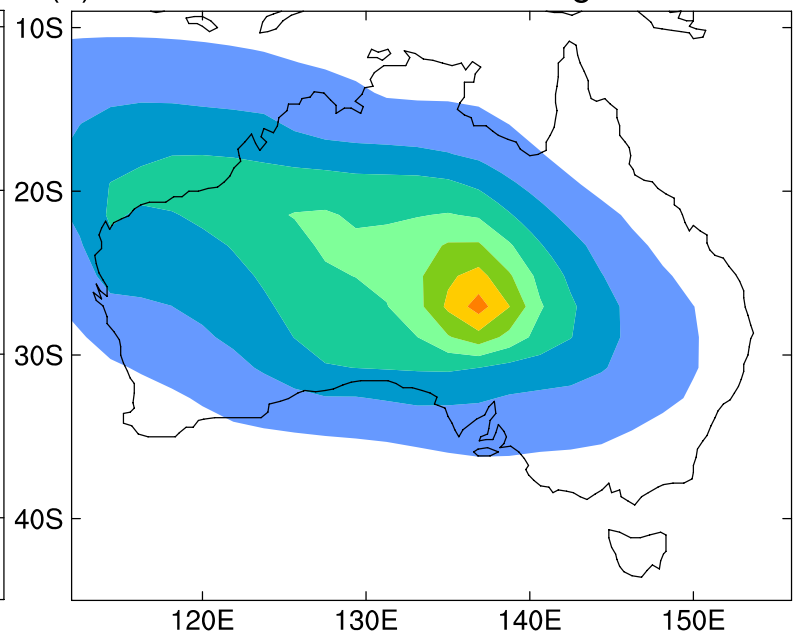

(d) SON modelled dust loading from Mk3.6

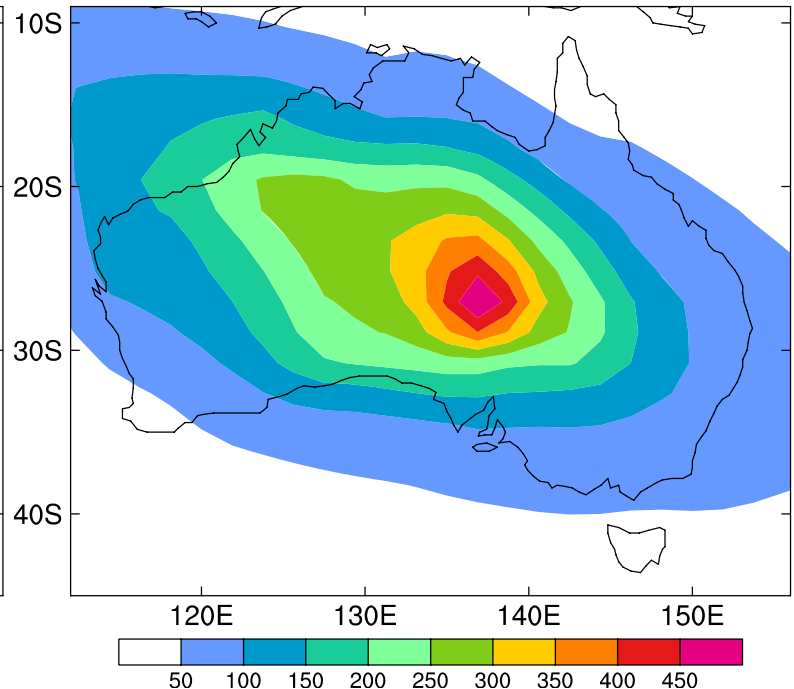

Fig. 2. Dust load over Australia (a) observed annual means, (b) simulated annual means, (c) observed for SON, (d) simulated for SON (in $\mathrm{mg} \mathrm{m}^{-2}$ ). Observations cover the period September 2002 to August 2007 for annual means, and September 2002 to November 2007 for SON.

quantities by repeating the last 60 years of the DUST run with the inclusion of an additional radiation call every three hours (which is the usual interval between radiation calls in the model). The global-mean top-of-atmosphere direct radiative effect of dust in the DUST run is $-0.82 \mathrm{~W} \mathrm{~m}^{-2}$ (shortwave) and $+0.26 \mathrm{~W} \mathrm{~m}^{-2}$ (longwave). These values are similar to those obtained in two recent modelling studies that also used updated refractive indices to represent less absorptive dust particles than previously assumed: Miller et al. (2006) obtained $-0.62 \mathrm{~W} \mathrm{~m}^{-2}$ (shortwave) and $+0.23 \mathrm{~W} \mathrm{~m}^{-2}$ (longwave), and Yoshioka et al. (2007) obtained $-0.92 \mathrm{~W} \mathrm{~m}^{-2}$ (shortwave) and $+0.32 \mathrm{~W} \mathrm{~m}^{-2}$ (longwave). Due to the relatively high SSA $(\sim 0.96)$ of dust, the top-of-atmosphere shortwave forcing is negative everywhere, unlike some other models, where more absorptive dust can give positive shortwave forcing over surfaces with high albedo. As in other models, surface shortwave forcing $\left(-2.19 \mathrm{~W} \mathrm{~m}^{-2}\right)$ is negative and surface longwave forcing $\left(+0.91 \mathrm{~W} \mathrm{~m}^{-2}\right)$ is positive. Over the major dust sources, longwave forcing can be comparable in magnitude to shortwave forcing, but it falls away more quickly with distance, since longwave forcing has a larger relative contribution from large particles. Also, dust shortwave forcing over oceans is enhanced in relative terms by the lower surface albedo. A useful recent summary of results from other models is given by Yue et al. (2010); this shows that the surface radiative forcing in our model is within the range of other results. The magnitude of both our shortwave and longwave surface forcing is larger than average, 
probably due to our relatively large dust burden.

Before attempting to draw conclusions about the effects of dust in the Mk3.6 simulations, it is useful to compare the simulated distribution of Australian dust with observed values. Our observed distribution is based on a spatial pattern derived from Advanced Along-Track Scanning Radiometer (AATSR) satellite retrievals for the period 2002-2008. A new algorithm for aerosol retrieval from AATSR has been developed, which enables the retrieval of aerosol optical depth (AOD) and identification of aerosol types. The algorithm will be discussed in two separate papers that are currently in preparation. It is based on classification of local aerosol types reported by Qin and Mitchell (2009), using a clustering analysis of sunphotometer observations at CSIRO Aerosol Ground Station Network (AGSNet) sites, which are affiliated with NASA's Aerosol Robotic Network (Mitchell and Campbell, 2004). Among the Australian aerosol classes is a dust aerosol, the particle size distribution of which allows dust mass loading to be derived from the AATSR AOD.

Figure 2 shows observed and modelled dust loading over Australia for annual-mean and SON conditions. The model is broadly successful at capturing the spatial pattern of Australian dust, with the Lake Eyre Basin in central-eastern Australia as the dominant dust source. There is some evidence of a high bias in the modelled results relative to the satellite retrievals, especially in SON. The noisier pattern in the satellite-retrieved values probably reflects, at least in part, the much shorter time period for the satellite record (six years as opposed to 160 years in the model).

We have also compared the annual cycle of simulated aerosol optical depth with sun-photometer measurements from Tinga Tingana, a dust-dominated site in the Strzelecki Desert of South Australia (approximately $140^{\circ} \mathrm{E}, 29^{\circ} \mathrm{S}$ ), which forms part of AGSNet. A 10-year aerosol climatology at this site (Mitchell et al., 2010) showed dual peaks in AOD in September and January, the former including a significant fine-particle mode characteristic of smoke from long-range transport, while the January peak was dominated by coarse particles characteristic of wind-blown dust.

Figure 3 compares the observed and modelled annual cycles of AOD. The observational cycle is the AOD from Mitchell et al. (2010) interpolated to $530 \mathrm{~nm}$, with vertical bars equal to one standard deviation. The modelled cycles show the seasonal variation of mid-visible AOD, both "total" and "dust only". The comparison suggests that the modelled total AOD is unrealistically high throughout the year, particularly during the spring and summer peaks. These peaks are not present in the model's "dust only" AOD, and are likely due to an excessive contribution to AOD from biomass burning in the model. This is especially true in January, when the biomass-burning emissions used in this version of the model are too large over eastern Australia; the emissions are based on satellite retrievals for the year 2000 (Ito and Penner, 2004, 2005), which are probably not representative of the long-term average. Plots of the modelled distribution

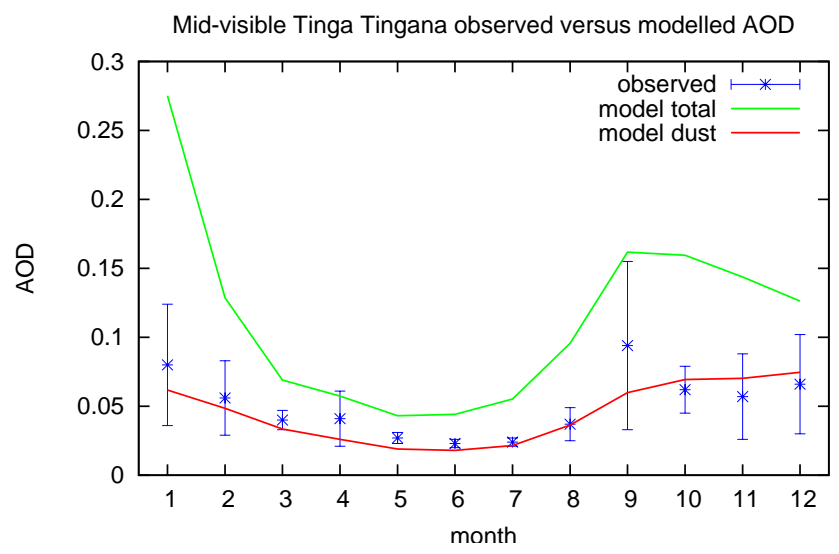

Fig. 3. Annual cycle of mid-visible aerosol optical depth at Tinga Tingana (approx. $140^{\circ} \mathrm{E}, 29^{\circ} \mathrm{S}$ ). Sun photometer-based observed monthly means are shown in blue, with error bars denoting the standard deviation of individual observations. Modelled optical depths due to dust (red curve) and all tropospheric aerosols (green curve) are taken from the DUST run.

of carbonaceous aerosol (not shown) indicate that the modelled AOD at Tinga Tingana is elevated by biomass-burning aerosol advected from northern Australia during the months of August to November, with a maximum effect in September. According to Mitchell et al. (2010), the observed AOD in September is also elevated by smoke aerosol from longrange transport, suggesting that this feature in the model is qualitatively realistic, though overestimated in magnitude.

In summary, the model qualitatively captures the annual cycle of AOD at Tinga Tingana, but overestimates the magnitude of the peaks in September and January due to an excessive contribution from biomass burning. Combining the results of Figs. 2 and 3, the model appears to moderately overestimate the Australian dust load and optical depth during the spring ( $\mathrm{SON}$ ) season, which will be the main focus of our study. This also seems consistent with our relatively large global dust load, and may be due to our treatment of sub-grid wind fluctuations in the dust emission scheme (Eq. 3).

\subsection{Simulation of mean Australian climate}

The simulation of seasonal-mean rainfall, surface air temperature and mean sea-level pressure (MSLP) in a shorter version of the DUST run was evaluated in detail by Rotstayn et al. (2010), who found an overall improvement relative to earlier versions of the model. Before we investigated the ENSO-related rainfall variability in the DUST and NODUST simulations, we considered whether there were any significant effects of Australian dust on the simulation of mean Australian climate by Mk3.6. When we compared the DUST and NODUST runs, we found that differences in simulated mean rainfall and MSLP were generally small and insignificant. 
(a) Mean observed SON rainfall (1978-2007)

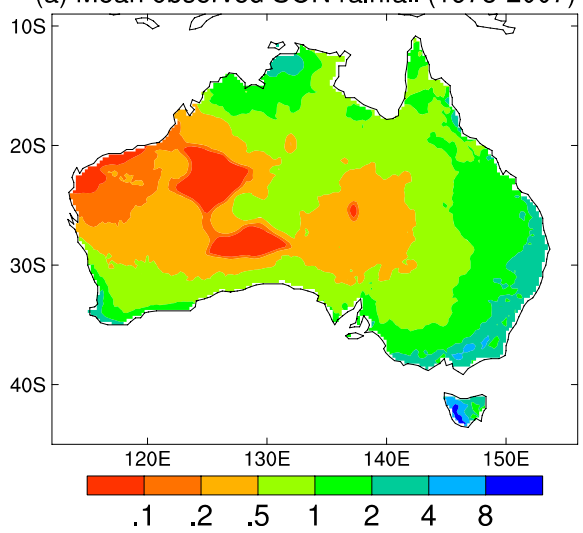

(b) Mean modelled SON rainfall, DUST run

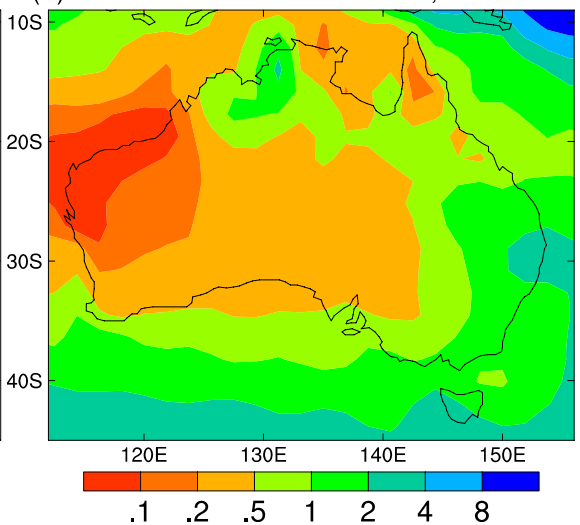

(c) Mean SON rainfall, DUST minus NODUST

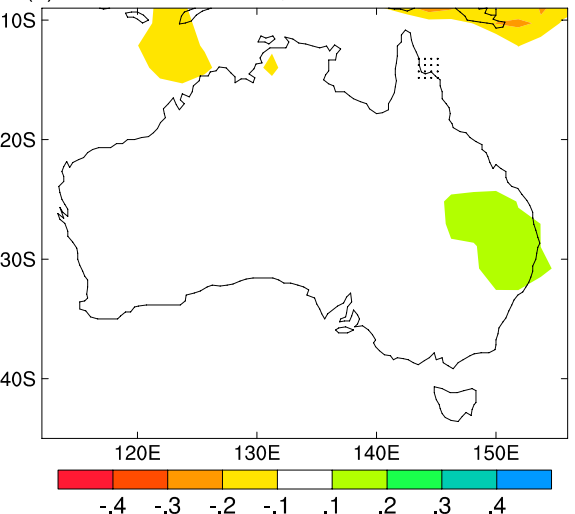

Fig. 4. Mean SON rainfall from (a) observations for 1978-2007, (b) the DUST run, and (c) the difference between the DUST and NODUST runs (in mm per day). In panel (c), stippling shows the (single) grid box where differences are significant at $5 \%$.

Since we will focus on variability of rainfall during SON, we show in Fig. 4 the mean SON observed rainfall from the Australian Water Availability Project (AWAP; Jones et al., 2009) and from the model. The DUST run (middle panel) is broadly able to capture the observed climatology shown in the left panel, although the model has a dry bias compared to the observations. The difference between the DUST and NODUST runs (right panel) confirms that, although there is an area in eastern Australia where the DUST run has slightly higher rainfall in SON, the differences are generally not statistically significant. This was also the case in other seasons (not shown).

However, there was a small but statistically significant increase of annual-mean surface air temperature over the Australian continent in the DUST run. This was seen more strongly in the daily minimum temperatures $(0.24 \mathrm{~K})$ than in daily maxima $(+0.09 \mathrm{~K})$, corresponding to a decrease in the diurnal temperature range. A reduction of the diurnal temperature range has been seen before, both in observations (Washington et al., 2006) and a global model (Yue et al., 2010). It's noteworthy that our model indicates a small increase of average daily maxima due to dust over Australia. This differs from the observational result of Washington et al. (2006) for Saharan dust in the Bodélé Depression, where daily maximum temperatures were lower in the presence of dust. However, our result appears to be not inconsistent with that of Yue et al. (2010), whose simulated afternoon temperatures over central and eastern Australia were increased in the presence of dust (their Figure 7b, which corresponds to $4 \mathrm{pm}$ over eastern Australia). This is an interesting result, but we do not consider it further in the present paper.

\subsection{Observed and modelled ENSO-rainfall relationships}

In this section, we will compare the ENSO-rainfall relationships in the DUST and NODUST runs with corresponding observed relationships during SON, using standard linear regression. Sea surface temperature (SST) observations are the $1^{\circ}$ gridded analysis from HadISST2 (Rayner et al., 2003), and rainfall observations are from AWAP (Jones et al., 2009). We follow the common practice of measuring the state of ENSO using SST averaged over the Niño 3.4 region $\left(170^{\circ} \mathrm{W}-120^{\circ} \mathrm{W}, 5^{\circ} \mathrm{S}-5^{\circ} \mathrm{N}\right)$. The standard deviation of Niño 3.4 SST (taking each SON average as a single data point) is $0.64 \mathrm{~K}$ in DUST and $0.63 \mathrm{~K}$ in NODUST (compared to $0.81 \mathrm{~K}$ in HadISST2). Thus, when we show the results of the linear regression relative to a $1 \mathrm{~K}$ change in Niño 3.4 SST, this represents somewhat less than $\mathrm{a} \pm 1$ standard deviation change.

Figure 5 shows observed and modelled relationships between Niño3.4 SST and Australian rainfall for the period 1901-2007. The observations (top row) confirm the results of earlier studies, that there is a strong relationship between ENSO and Australian rainfall in spring, mainly over the eastern two-thirds of the continent (McBride and Nicholls, 1983; Ropelewski and Halpert, 1987). In the DUST run (middle row), the model is rather successful at capturing the observed relationships, with significant correlations between -0.25 and -0.55 over most of eastern Australia, and regression slopes that are comparable to the observed values. Note that, due to the model's relatively coarse resolution (approximately $1.9^{\circ}$, compared to $0.25^{\circ}$ in the observations), it would not be expected to resolve the enhanced rainfall over the Alps in south-eastern Australia, or along the Queensland coast. Over some parts of central-eastern Australia, the modelled correlations and regression slopes are somewhat stronger than the observed values. In the NODUST run (bottom row), 
Correlation of SON rainfall vs Nino 3.4 SST, observed Regression of SON rainfall vs Nino 3.4 SST, observed
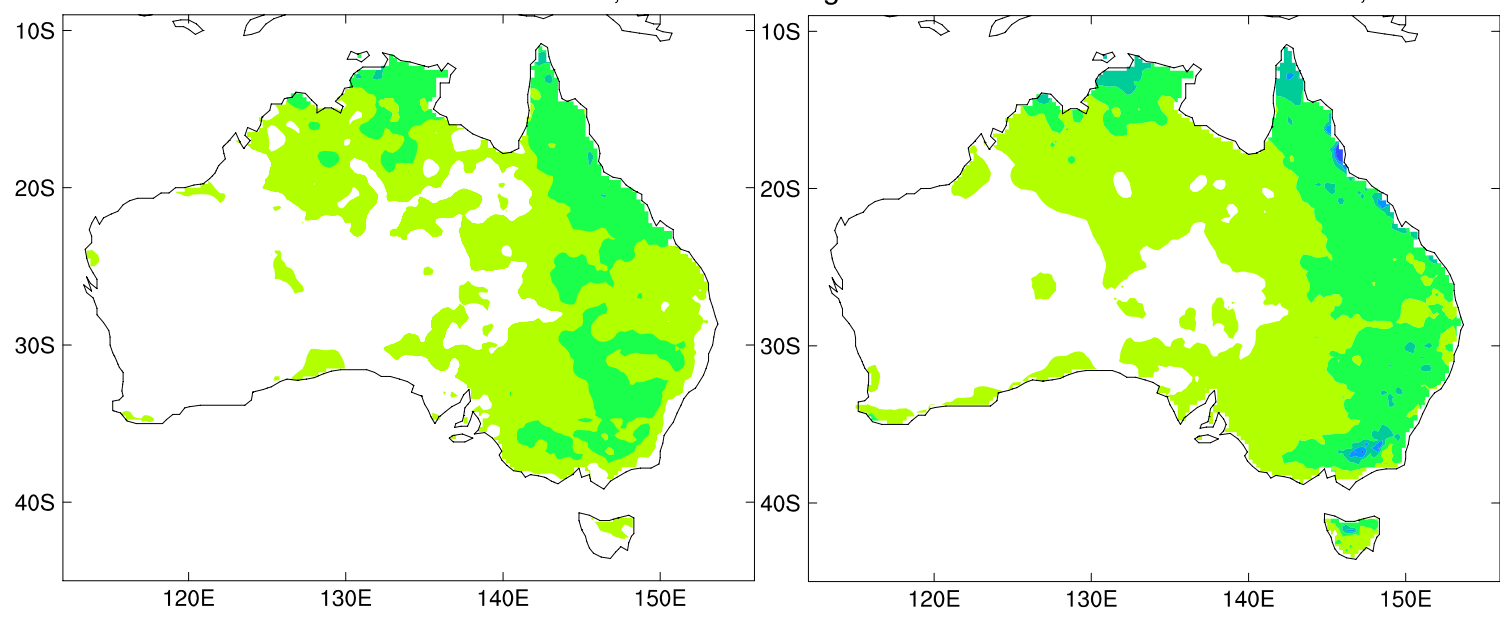

Correlation of SON rainfall vs Nino 3.4 SST, DUST run

Regression of SON rainfall vs Nino 3.4 SST, DUST run
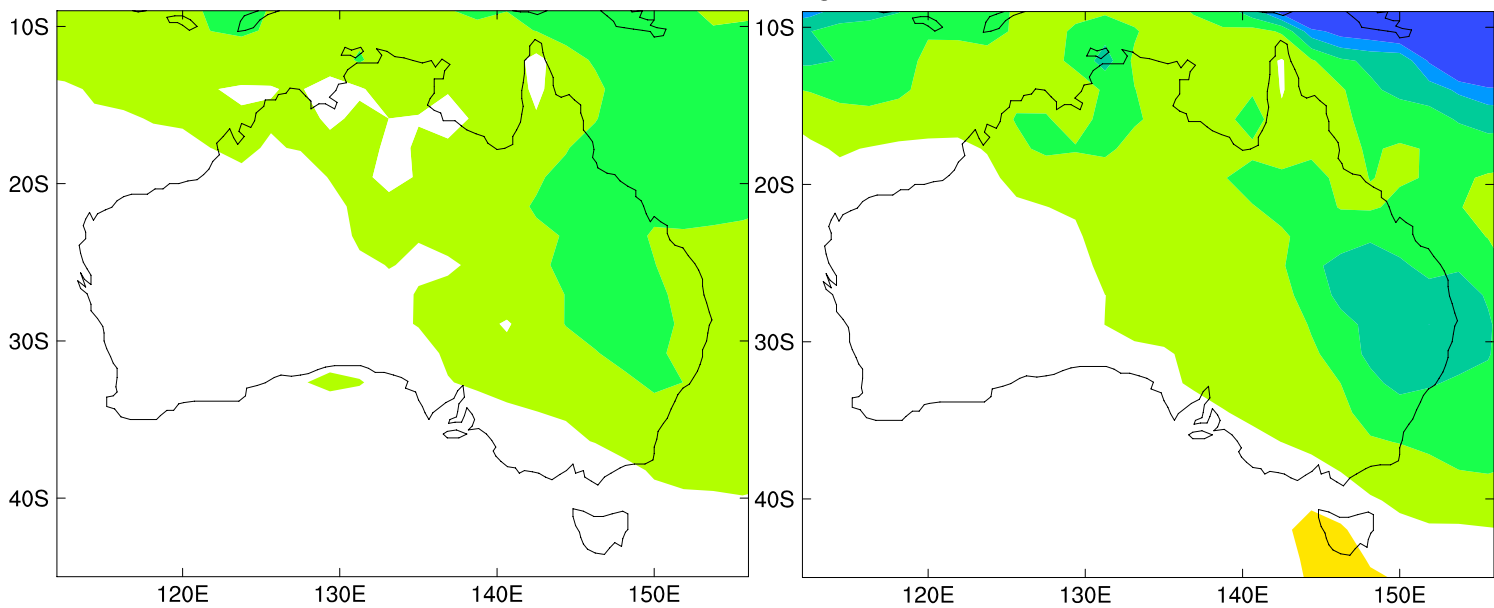

Correlation of SON rainfall vs Nino 3.4 SST, NODUST run

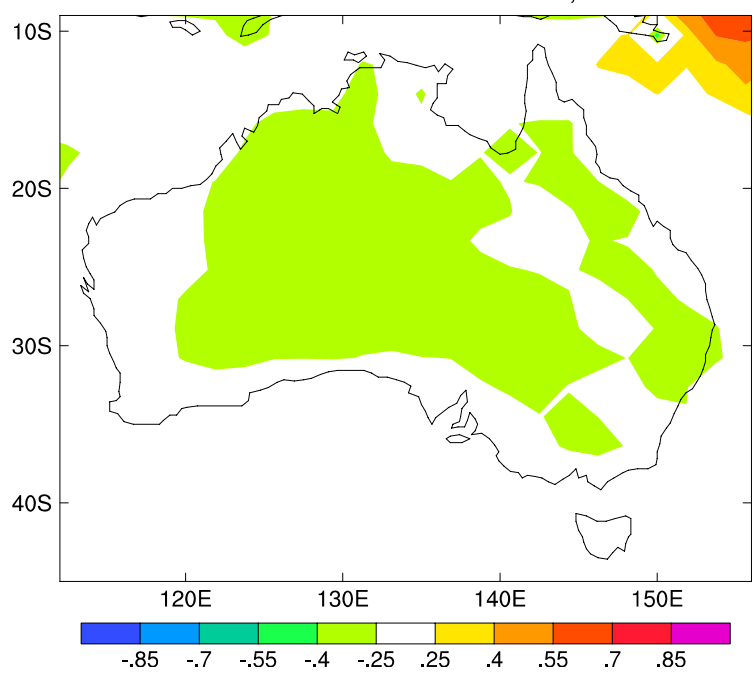

Regression of SON rainfall vs Nino 3.4 SST, NODUST run

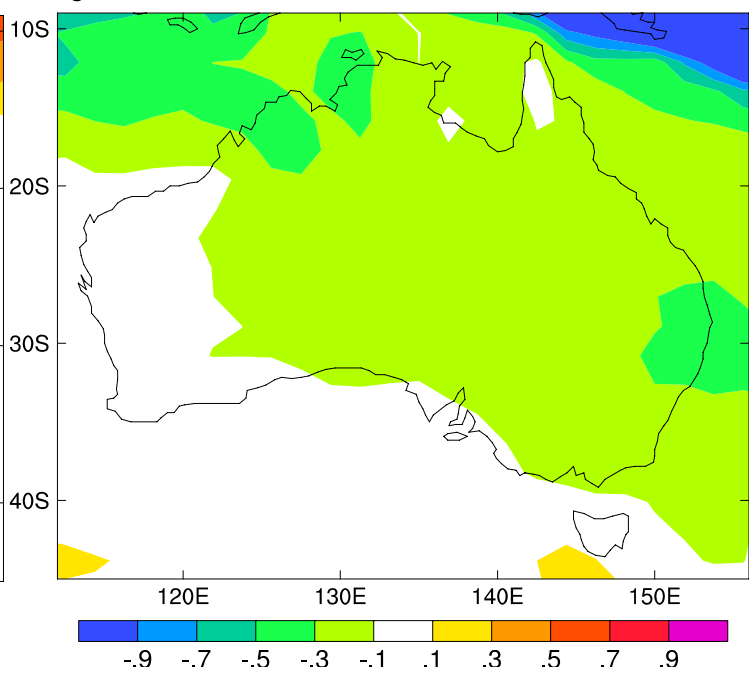

Fig. 5. Observed and modelled relationships between Niño3.4 SST and Australian rainfall during SON: correlations (left) and regression slopes (right, in mm per day per Kelvin), from observations for 1901-2007 (top), the DUST run (middle) and the NODUST run (bottom). 
Regression of SON rainfall versus Nino3.4 SST, DUST minus NODUST

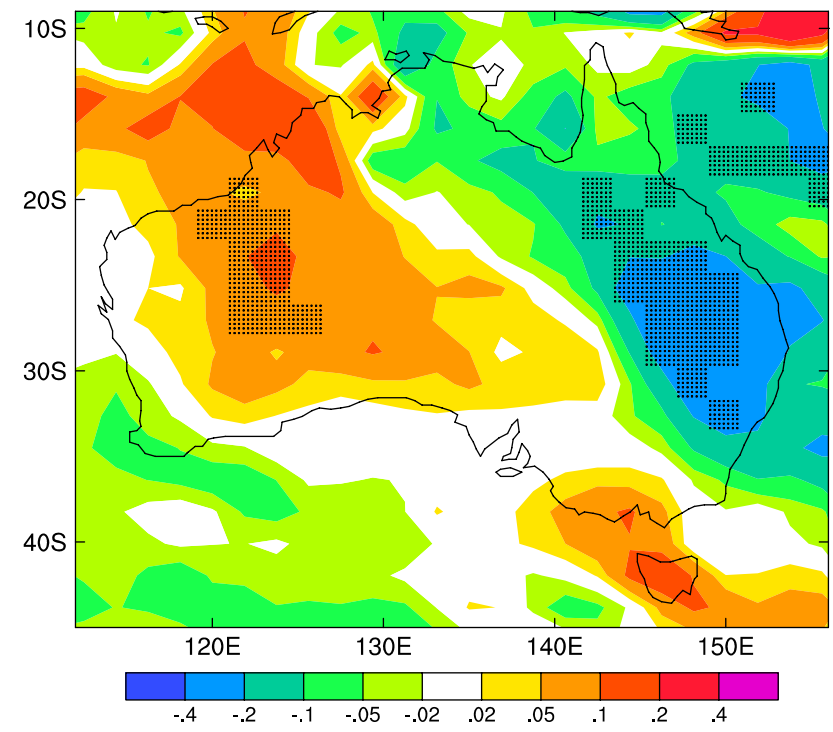

Fig. 6. Difference of the Niño3.4 SST - rainfall regression slopes between the DUST and NODUST runs for SON. Stippled regions are significant at $5 \%$.

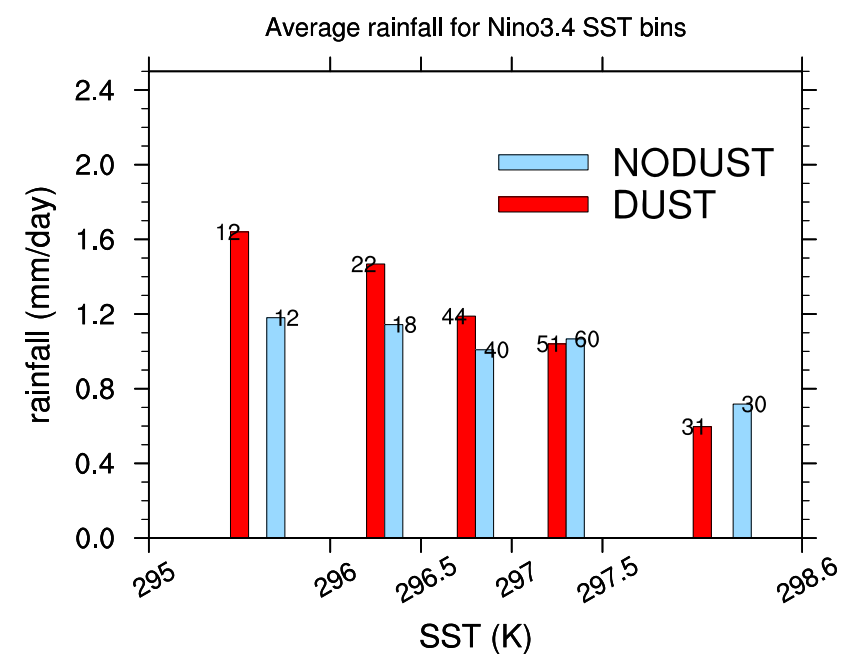

Fig. 7. Rainfall for Niño3.4 SST bins, averaged over the stippled points in eastern Australia from Fig. 6. Red bars are from the DUST run, and blue bars are from the NODUST run. The number of points in each SST bin is shown near the top of each bar. The width of each SST bin is $0.5^{\circ}$, except for the first and last bins, which have width of roughly $1^{\circ}$.

the ENSO-rainfall relationships are markedly weaker, and they tend to agree less well with the observed relationships. Over substantial areas of eastern Australia, the correlations are not significant $(|r|<0.25)$. The region of significant correlation also extends further to the west in NODUST, which agrees less well with the observed relationship.
Figure 6 shows the difference of the Niño3.4 SST - rainfall regression slopes between the DUST and NODUST runs. Statistical significance is assessed using a t-test for the difference of regression slopes (Zar, 1996, chapter 17). This plot confirms that inclusion of Australian dust amplifies the modelled ENSO-rainfall relationship over eastern Australia and weakens it over parts of western Australia. In total, there are 19 grid points over eastern Australia (stippled in the plot) where the Niño3.4 SST - rainfall regression slope is significantly different in the two runs.

Is the stronger ENSO-rainfall relationship over eastern Australia in the DUST run due to wet years becoming wetter, dry years becoming drier, or both? For each of the SON seasons, we averaged the rainfall over the stippled points in eastern Australia in Fig. 6, and plotted a scatter diagram of these 160 data points against Niño3.4 SST for both runs (not shown). This confirmed the above result that the regression slope is steeper in DUST than in NODUST, and the correlation between Niño3.4 SST and rainfall is also markedly stronger in DUST $(r=-0.48)$ than in NODUST $(r=-0.27)$. To make this clearer, we sorted the data points into $0.5^{\circ}$ Niño3.4-SST bins, and plotted them as a histogram in Fig. 7. This confirms that wet years are wetter and dry years are drier in the DUST run (red bars) than in the NODUST run (blue bars). There is a monotonic change in the effect of dust with increasing SST: there is a dust-induced rainfall increase of $39 \%, 28 \%$ and $18 \%$ in the first, second and third SST bins, and a dust-induced rainfall decrease of $2.5 \%$ and $17 \%$ in the fourth and fifth SST bins. This also shows that, even in relative terms, the effect of dust is stronger in wet years than in dry years. It is also seen that, averaged over the points used to construct the histogram, the DUST run has slightly higher rainfall in SON than the NODUST run; this is consistent with the small (and nonsignificant) change in mean SON rainfall shown in Fig. 4c.

\section{Mechanism of dust-ENSO feedback}

A first indication of the mechanism is given in Fig. 8, which compares vertical profiles of moist static energy, averaged over the same points that were used to construct the histogram in Fig. 7. For each run, we created composites of years classified as "El Niño" (Niño3.4 SST more than one standard deviation above the mean), "La Niña" (Niño3.4 SST more than one standard deviation below the mean) and "neutral" (Niño3.4 SST within one standard deviation of the mean). The black curve shows the difference between all years of the DUST and NODUST runs; in the mean, the profile is slightly more unstable in the DUST run, consistent with the small difference in mean SON rainfall shown in Fig. 4c. The other curves confirm that the profile is much more stable in El Niño years (red, magenta) than in La Niña years (green, blue). Further, DUST shows enhanced 


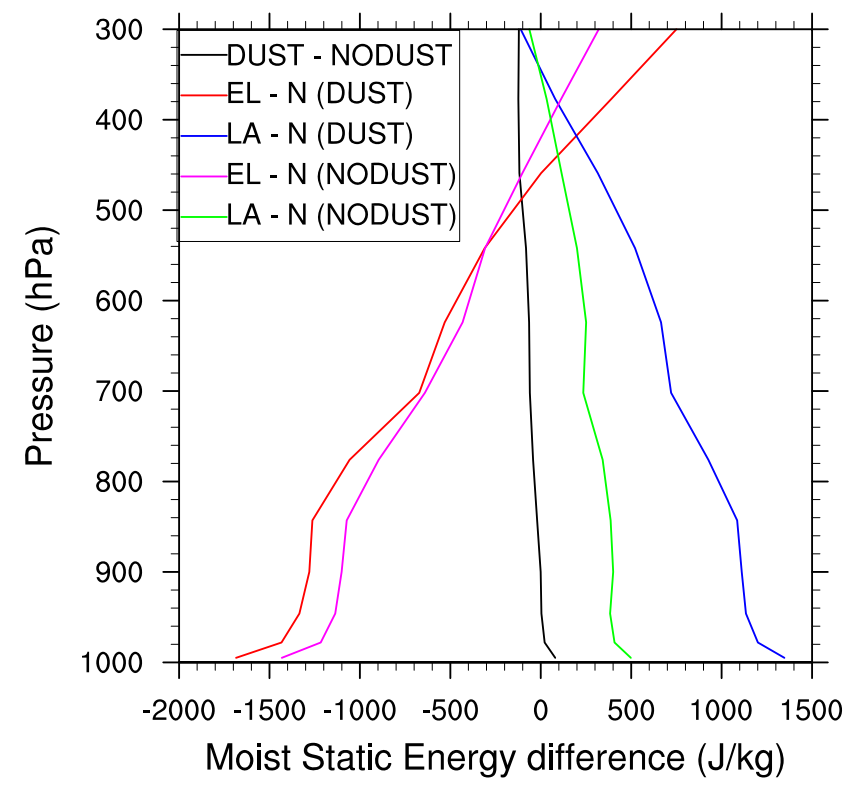

Fig. 8. Differences in the vertical profile of moist static energy, averaged over the stippled points in eastern Australia from Fig. 6: DUST minus NODUST (black), El Niño minus neutral for DUST (red) and NODUST (magenta), La Niña minus neutral for DUST (blue) and NODUST (green).

moist static stability (instability) in El Niño (La Niña) years compared to NODUST.

To explore this further, Fig. 9a shows the difference (DUST minus NODUST) of the regression slopes of moist static instability versus Niño3.4 SST, where moist instability is defined as the difference of moist static energy between near-surface air and the $700 \mathrm{hPa}$ level. (We chose $700 \mathrm{hPa}$ as the level of maximum cloud fraction over eastern Australia, but Fig. 8 suggests that the precise choice of levels is not critical.) Relative to NODUST, the DUST run shows an amplification of the change in stability in response to ENSO, over most of eastern Australia. The strongest amplification occurs over north-eastern Australia, which agrees well with the region where the DUST run shows a significantly different rainfall-Niño3.4 SST relationship in Fig. 6. Figure 9b and c show that this pattern is due to changes in moisture, whereas there is a smaller offsetting effect due to changes in temperature over some areas. At least in part, this offset is caused by a negative feedback due to latent heating: More rainfall implies more diabatic heating due to condensation within the cloud layer, and near-surface cooling due to a moister surface and evaporation of rainfall.

The predominance of moisture-driven effects in Fig. 9 strongly suggests that the dust-rainfall feedback mechanism is related to moisture transport, rather than local dust-induced radiative effects as hypothesised by Rotstayn et al. (2010). In the following paragraphs, we show that in the DUST run this is related to increased dust radiative forcing over the oceans

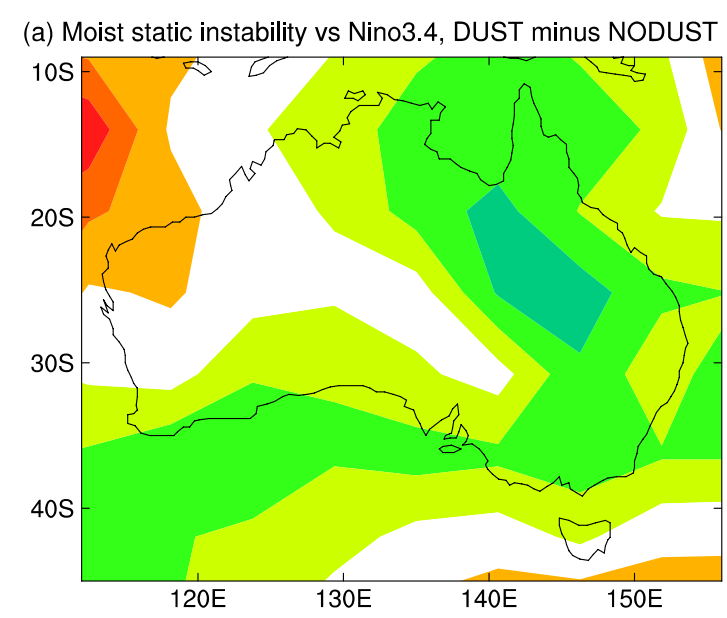

(b) Moist static instability (Q) vs Nino3.4, DUST minus NODUST

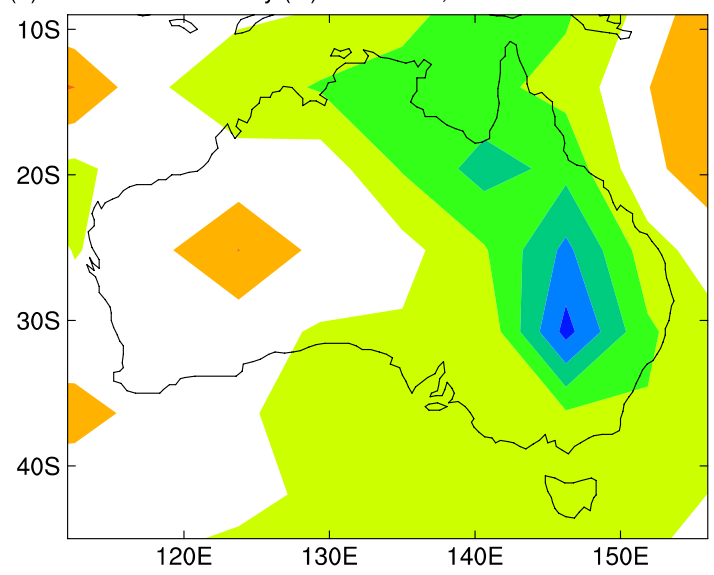

(c) Moist static instability (T) vs Nino3.4, DUST minus NODUST

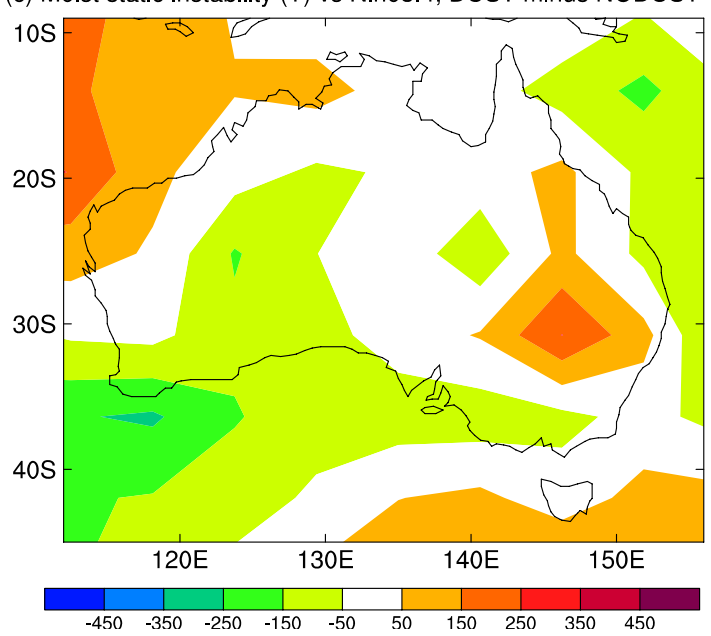

Fig. 9. Difference of the regression slopes of moist instability versus Niño3.4 SST between the DUST and NODUST runs for SON (in $\mathrm{J} \mathrm{kg}^{-1} \mathrm{~K}^{-1}$ ). Moist instability is defined as the difference of moist static energy $\left(\mathrm{J} \mathrm{kg}^{-1}\right)$ between near-surface air and the $700 \mathrm{hPa}$ level: (a) based on total moist static energy, (b) contribution of moisture changes, $(\mathbf{c})$ contribution of temperature changes. 


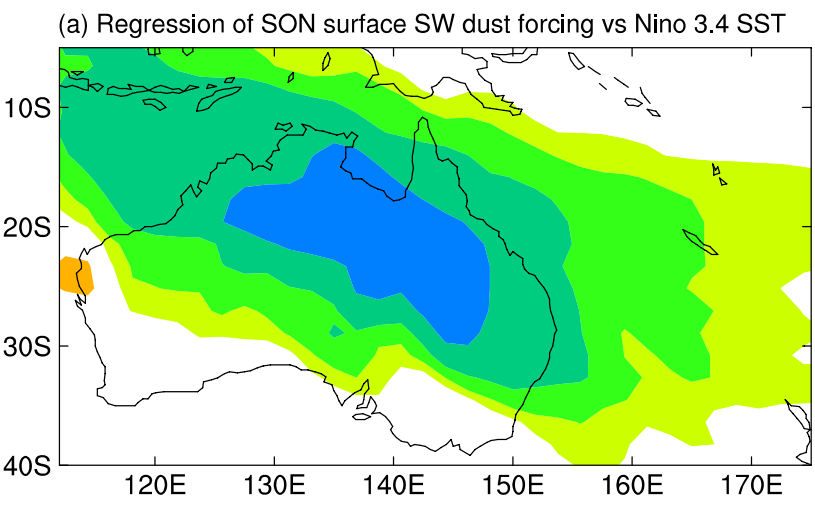

(b) Regression of SON surface LW dust forcing vs Nino 3.4 SST

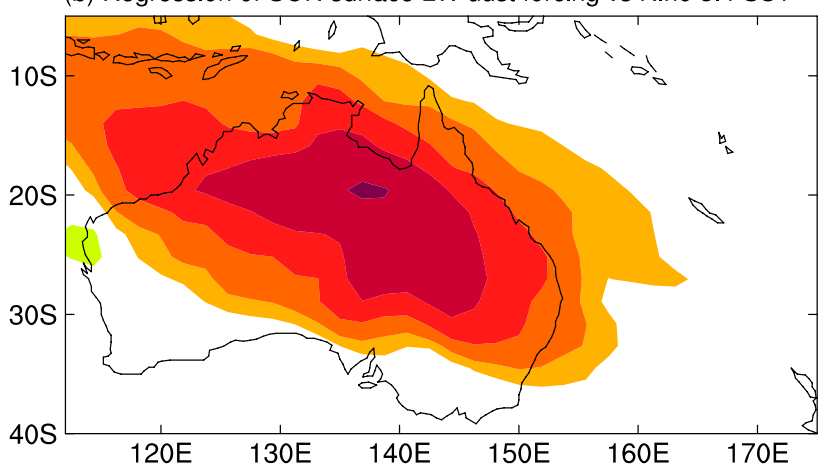

(c) Regression of SON surface net dust forcing vs Nino 3.4 SST

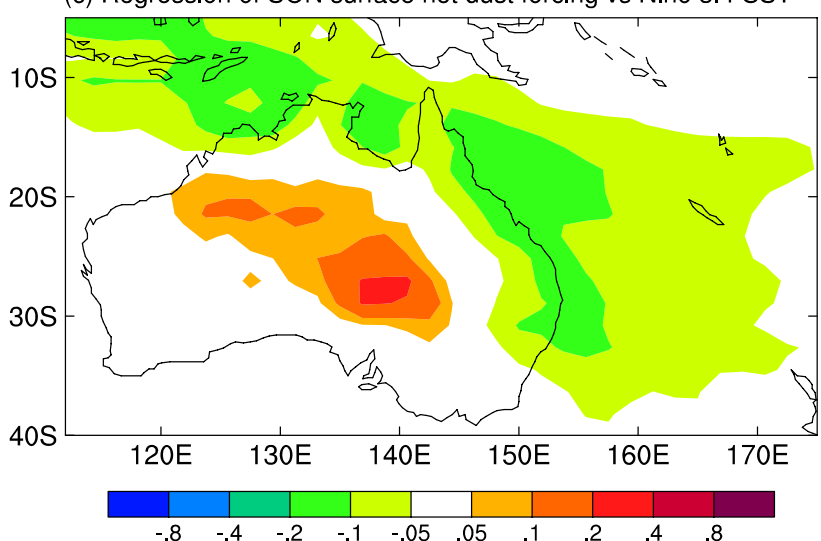

Fig. 10. Regression slopes of dust surface radiative forcing versus Niño3.4 SST from the DUST run for SON (in $\mathrm{W} \mathrm{m}^{-2} \mathrm{~K}^{-1}$ ): (a) shortwave, (b) longwave, (c) net.

east of Australia under El Niño conditions, and vice versa under La Niña conditions. This drives a decrease (increase) of surface evaporation under El Niño (La Niña) conditions. The anomalous moisture evaporated from the ocean surface is advected towards Australia by the climatological easterly trade winds, increasing moisture convergence and the amplitude of the ENSO-induced rainfall cycle over eastern Australia.

Rotstayn et al. (2010) showed that dust loading over Australia in Mk3.6 is strongly correlated with ENSO, especially

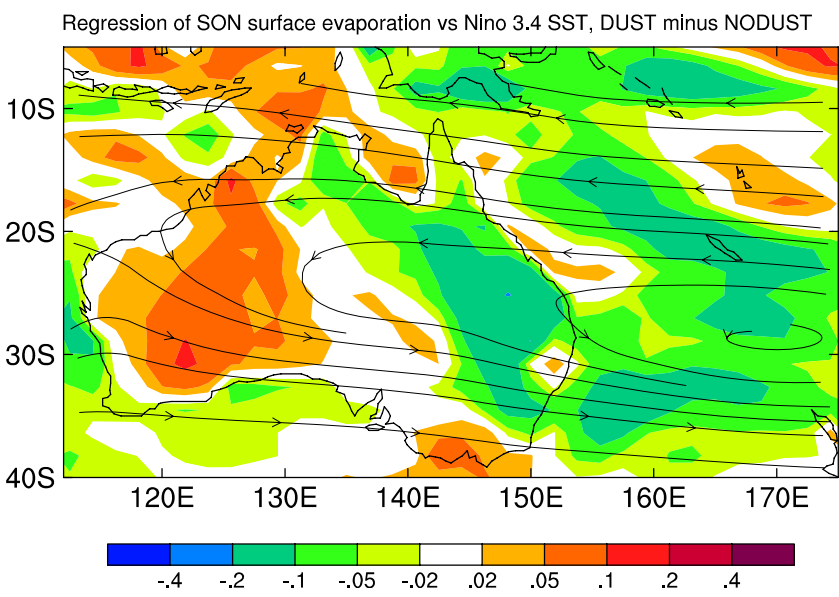

Fig. 11. Difference of the regression slopes of surface evaporation versus Niño3.4 SST between the DUST and NODUST runs for SON (shading, in mm per day per Kelvin). Streamlines show the mean SON 850-hPa flow in the DUST run.

over eastern and northern Australia. This arises because rainfall strongly affects the source function for dust (via its effect on soil moisture) as well as the sink via wet deposition. We thus expect that dust radiative forcing will also be correlated with ENSO in the DUST run. Figure 10 shows the regression of surface dust radiative forcing against Niño3.4 SST. As expected, shortwave forcing decreases (becomes more negative) with increasing Niño3.4 SST, whereas longwave forcing increases with increasing Niño3.4 SST. The regression of net forcing (Fig. 10c) shows that, over the oceans and coastal regions of Australia, the shortwave effect is stronger, whereas the longwave effect is stronger over the interior of the continent. As mentioned in the discussion of Fig. 1, the predominance of shortwave forcing away from the primary source occurs because dust longwave forcing has a larger relative contribution from large particles, and shortwave forcing over oceans (and in coastal regions) is enhanced by the lower surface albedo.

Figure 11 shows the difference (DUST minus NODUST) of the regression slopes of surface evaporation versus Niño3.4 SST, overlaid with streamlines showing the mean 850-hPa flow in the DUST run. Over Australia, the differences suggest that ENSO-induced changes in evaporation are substantially a response to changes in rainfall (Fig. 6); in the DUST run, less (more) rainfall under El Niño (La Niña) conditions over eastern Australia causes less (more) evaporation, enhancing the negative regression slope. Over the Pacific Ocean east of Australia, the regression slope is also generally more negative in the DUST run. There, the supply of moisture is effectively unlimited. However, reduced net radiation at the surface must be balanced by weaker latent and sensible heat fluxes (Ramanathan et al., 2001; Roderick and Farquhar, 2002; Liepert et al., 2004). Miller et al. (2004) found that, globally, dust radiative forcing at the surface is balanced 
predominately by a reduction in the latent heat flux, with the largest effect over oceanic regions downwind of dust source regions (their Fig. 14). At lower latitudes, the climatological easterly winds advect moisture from the Pacific Ocean towards Australia, suggesting that, in the DUST run, increased (decreased) evaporation from the sea surface in La Niña (El Niño) years will increase (decrease) the moisture available for precipitation. Note that there are some areas east of Australia where the change in regression slope between DUST and NODUST is of the opposite sign, e.g. the region immediately off the north-east coast. These are areas where a larger ENSO-related change in rainfall and associated cloudiness in the DUST run outweighs the effect of changes in dust.

The above results suggest a mechanism whereby dustinduced changes in moisture transport from the oceans to the east and north-east of Australia amplify the ENSO-related rainfall variability over eastern Australia. Moisture transport and the associated convergence field is most accurately calculated by vertical integration of the horizontal flux of specific humidity, on a time scale short enough to resolve synoptic variability (e.g. Watterson, 1998). However, we only saved monthly mean model output from the 160-year runs, and when we extended the DUST run for a short period to compare the calculation using monthly mean winds and specific humidities with a similar calculation using threehourly data, we found that neglect of the "transient-flow" terms leads to substantial errors (not shown). An alternative method is to use the equation for the water vapour balance of an atmospheric column in equilibrium, namely

$-\nabla \cdot M_{q}=P-E$

where $\boldsymbol{M}_{\boldsymbol{q}}$ is the horizontal flux of specific humidity integrated over the atmospheric column, $E$ is evaporation of water vapour from the underlying surface, and $P$ is precipitation (e.g. Perlwitz and Miller, 2010). Equation (4) can be used to estimate the contribution to precipitation from moisture convergence $\left(-\nabla \cdot \boldsymbol{M}_{\boldsymbol{q}}\right)$, assuming no net accumulation of moisture in the column. We verified that changes in column water vapour during the $\mathrm{SON}$ season are small compared to the other terms in Eq. (4), suggesting that $P-E$ is a good proxy for moisture convergence, though this method does not provide vectors that show the direction of moisture transport.

The colour shading in Fig. 12 shows the difference (DUST minus NODUST) of the regression slopes of moisture convergence (Eq. 4) against Niño3.4 SST. Under La Niña conditions, there are substantial areas of increased moisture convergence over eastern Australia, and substantial areas of increased moisture divergence over the Pacific Ocean. The streamlines show the regression against Niño3.4 SST of lowlevel moisture advection by the mean SON flow in the DUST run, with arrows reversed, to indicate that the direction of enhanced moisture transport under La Niña conditions is from the Pacific Ocean towards Australia. (We do not show streamlines or vectors to represent the difference between

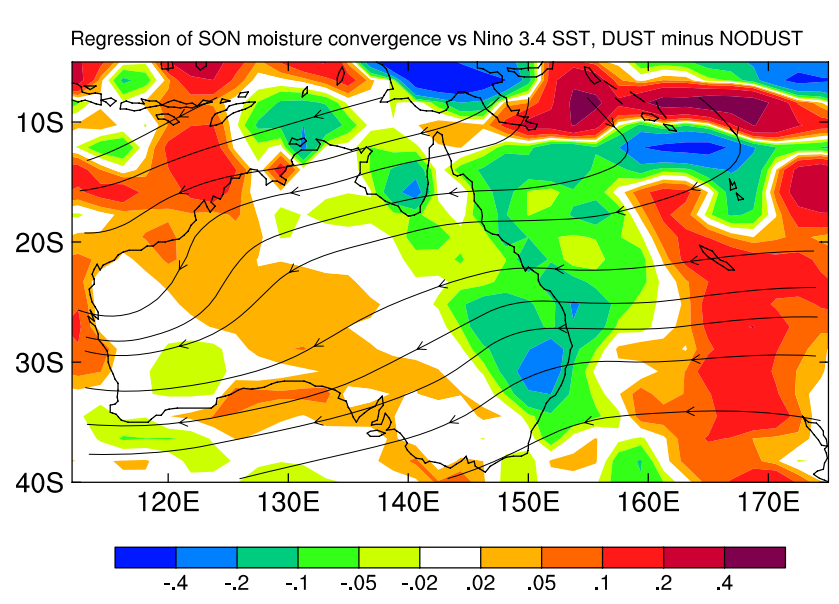

Fig. 12. Difference of the regression slopes of moisture convergence versus Niño3.4 SST between the DUST and NODUST runs for SON (shading, in mm per day per Kelvin). Streamlines show the regression against Niño3.4 SST of moisture advection by the mean SON flow in the DUST run, integrated from the surface to approximately $700 \mathrm{hPa}$. On the streamlines, the arrows are reversed, to show the direction of enhanced moisture transport under La Niña conditions.

DUST and NODUST, because, as discussed above, the calculation of moisture transport based on monthly mean fields is not very accurate, so the streamlines are illustrative rather than quantitative.) The pattern of moisture convergence and the direction of enhanced moisture transport under La Niña conditions provide further evidence that changes in moisture convergence due to dust-induced changes in evaporation from the Pacific Ocean increase the amplitude of the ENSOrelated rainfall cycle over eastern Australia in our model.

Why is a weaker ENSO-rainfall relationship seen over parts of north-western Australia in the DUST run? We plotted vertical circulations, but were unable to find evidence of a "monsoon-like" circulation change over the north-west linked to the dust-induced changes over eastern Australia, along the lines of the mechanism in Stephens et al. (2004) (not shown). A more likely explanation relies on a positive feedback between moist instability and convection over eastern Australia, where the magnitude of the difference (DUST minus NODUST) in the regression slope of rainfall (Fig. 6) is greater than that of moisture convergence (Fig. 12). This suggests that, under La Niña conditions in the DUST run, increased moist instability triggers increased rainfall in the north-east (by an amount that exceeds the increase of moisture convergence). This depletes the atmosphere of moisture, so advection of moisture towards north-western Australia by the climatological easterly winds is reduced.

It is interesting that the response of evaporation from the ocean surface east of Australia (Fig. 11) is larger than expected from a direct response to surface dust radiative forcing (Fig. 10c); for example, evaporation of $0.1 \mathrm{~mm}$ per day corresponds to a latent heat flux of roughly $2.9 \mathrm{~W} \mathrm{~m}^{-2}$. We 


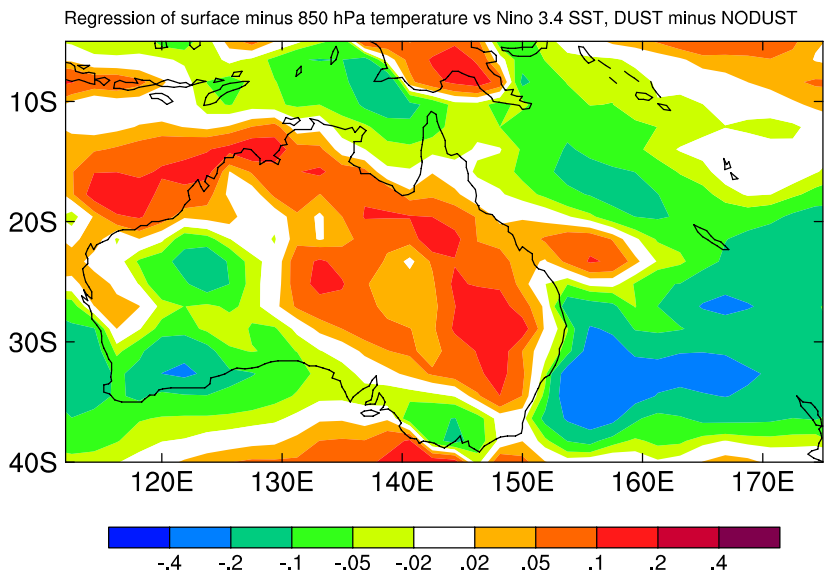

Fig. 13. Difference (DUST minus NODUST) of the slope of the regression against Niño3.4 SST of surface temperature minus 850$\mathrm{hPa}$ temperature for SON (in Kelvin per Kelvin).

looked at (and rejected) various possible explanations, including changes in near-surface wind speed, cloud-radiative forcing or the vertical profile of latent heating.

A more likely mechanism is that the change in the turbulent flux of latent heat from the ocean surface is enhanced by changes in the stability of the boundary layer induced by dust atmospheric heating. Figure 13 shows the difference (DUST minus NODUST) of the slope of the regression against Niño3.4 SST of surface temperature minus $850-\mathrm{hPa}$ temperature. Over most of the south-west Pacific Ocean, the DUST run has a more (less) stable boundary layer under El Niño (La Niña) conditions. The region where this effect occurs over the south-west Pacific agrees remarkably well with the region where the response of surface evaporation is enhanced in Fig. 11. This is suggestive of the mechanism seen in previous studies of absorbing aerosols, where heating of the lower troposphere combines with cooling of the surface to stabilise the lower atmosphere (e.g., Satheesh and Moorthy, 2005).

To examine dust-induced radiative heating of the lower atmosphere over the south-west Pacific Ocean, we plotted vertical profiles of dust concentration and dust radiative heating from the DUST run, averaged over the region $155-170^{\circ} \mathrm{E}$ and $15-35^{\circ} \mathrm{S}$. Composites of El Niño and La Niña years were created using the same method as in Fig. 8. Figure 14a shows that the vertical profile of dust concentration in the DUST run peaks between about 800 and $700 \mathrm{hPa}$; this differs from the time-averaged profile over the Australian continent, where dust concentration decreases with height (not shown). Shortwave heating (Fig. 14b) peaks around $700 \mathrm{hPa}$, close to the level of maximum dust concentration. The longwave heating profile (Fig. 14c) shows cooling within the layer of maximum dust concentration, and warming below, consistent with earlier studies (e.g., Highwood et al., 2003, their Figure 10). Shortwave and longwave heating tend to cancel each other within the main dust layer, but near the surface their warming effect is additive, and the net heating has a peak between about 950 and $900 \mathrm{hPa}$ (Fig. 14d). Not surprisingly, dust concentrations and radiative heating rates are enhanced in El Niño years relative to La Niña years. Figure 14d shows that dust atmospheric heating will tend to stabilise the boundary layer relative to the ocean surface, more so in El Niño years than in La Niña years.

Figure 15 shows differences (DUST minus NODUST) of the vertical temperature profile, averaged over the same region as in Fig. 14. This confirms that, in the DUST run, the layer between the surface and $850 \mathrm{hPa}$ has a more (less) stable temperature profile in El Niño (La Niña) years. The treatment of boundary-layer turbulence in the model is based on stability-dependent K-theory, so vertical fluxes of moisture will be increased when the temperature profile is less stable. The black curve in Fig. 15 shows that, averaged over all years, there is remarkably little difference in the atmospheric temperature profile between the DUST and NODUST runs, although the DUST run is slightly cooler at the surface. It is initially surprising that the ENSO-related anomalies have more effect than the average dust forcing, which is of larger magnitude than the anomalies. This result is analogous to what we found over the Australian continent, where dustinduced changes in mean rainfall were small compared to dust-induced changes in ENSO-related rainfall variability. It can be understood as follows: The time- and spatially averaged radiative effect of Australian dust is to cool the surface and heat the lower atmosphere. The top-of-atmosphere forcing is relatively small, and to first order there is approximate cancellation between surface cooling and atmospheric heating. When averaged over a decade or more, energy transport by the atmosphere and the ocean and energy transfer between the atmosphere and ocean ensure that the effects of the forcing on SST and atmospheric circulation become small. However, on shorter time scales, dust-induced anomalies in SST and atmospheric stability, such as those driven by ENSO, can persist and exert substantial climatic effects. An important aspect of this is likely to be the slow response of ocean circulation to an applied forcing.

\section{Summary and conclusions}

We compared two 160-year coupled atmosphere-ocean simulations of modern-day climate using the CSIRO Mk3.6 GCM. The DUST simulation included an interactive treatment of mineral dust and its direct radiative effects. This was a longer version of a similar run described by Rotstayn et al. (2010), who noted an improved simulation of Australian rainfall variability in Mk3.6 compared to its predecessor (Mk3.5) and several other GCMs. They hypothesised that "active" dust (which interacts with the model's hydrological cycle) might contribute to the improved simulation in Mk3.6 relative to Mk3.5. Their hypothesis was based on qualitative 
(a) Dust concentration $(\mathrm{ug} / \mathrm{m} 3)$

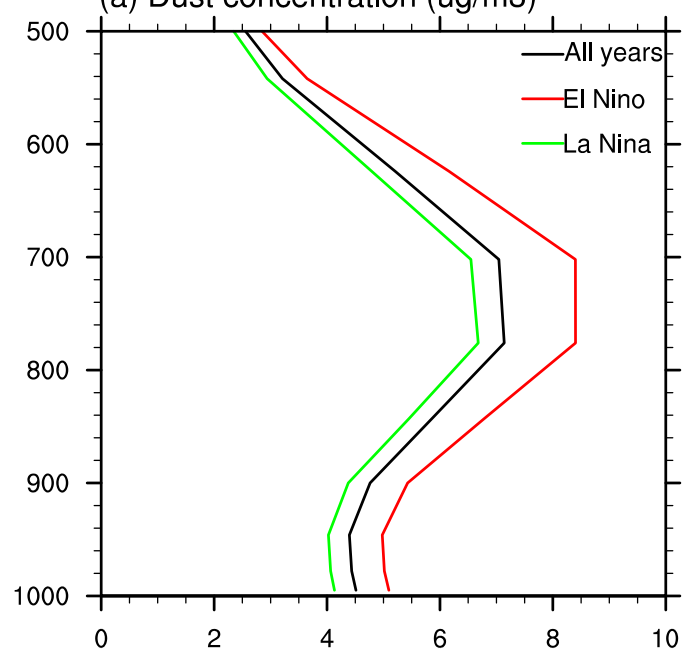

(c) LW dust heating (K/day)

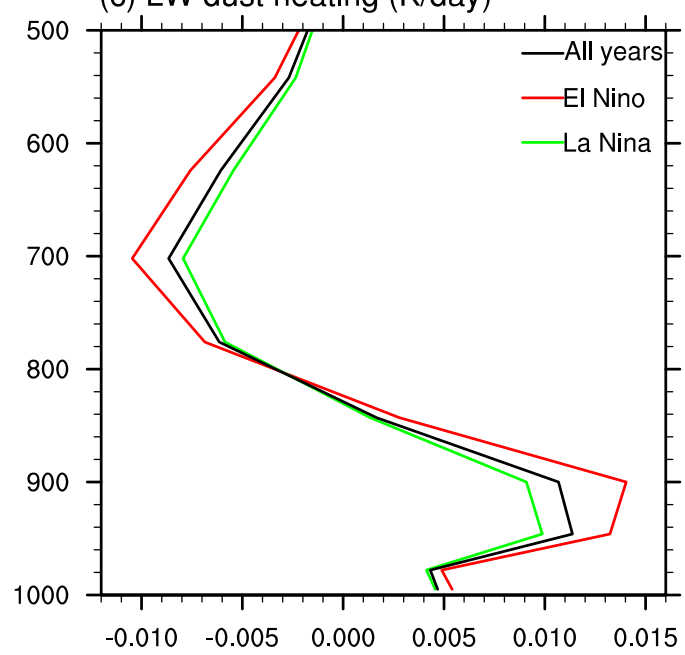

(b) SW dust heating (K/day)

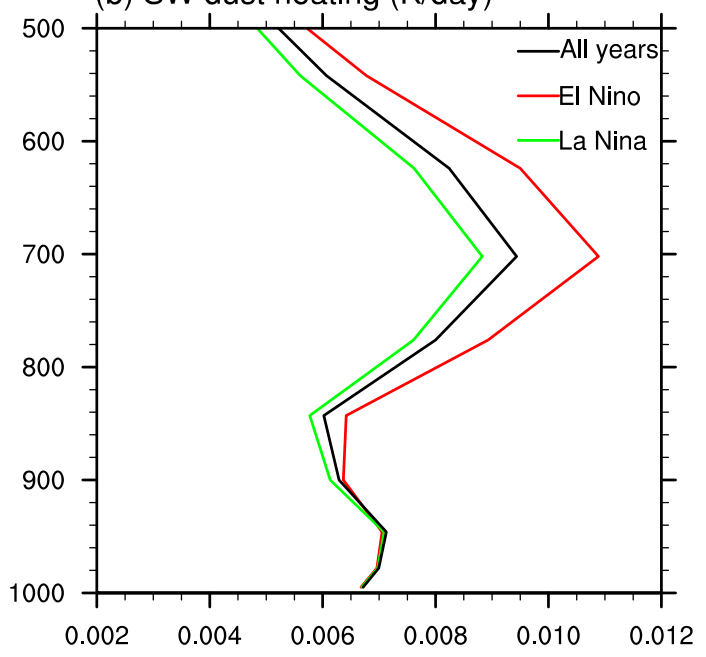

(d) Net dust heating (K/day)

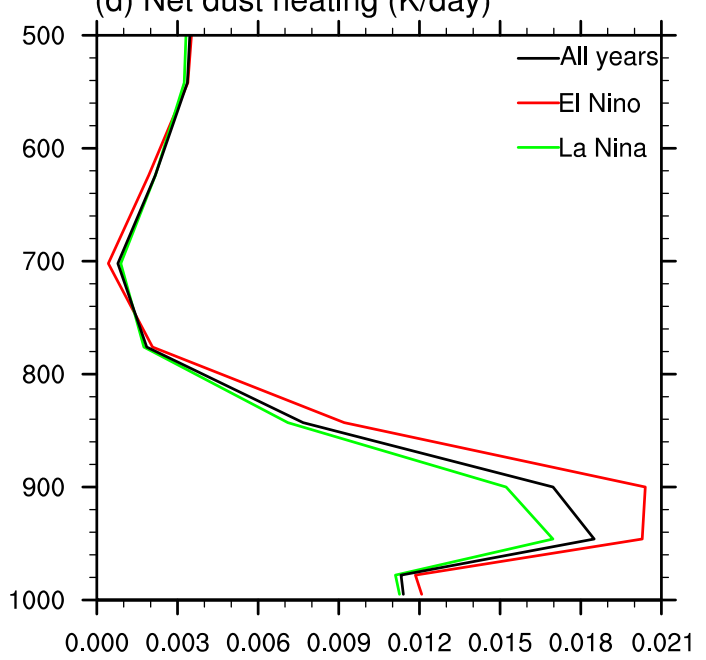

Fig. 14. Vertical atmospheric profiles from the DUST run, averaged over a region in the south-west Pacific Ocean $\left(155-170^{\circ} \mathrm{E}\right.$ and $15-$ $35^{\circ} \mathrm{S}$ ): (a) dust concentration, (b) shortwave, (c) longwave, (d) net dust radiative heating rates. Composites of El Niño and La Niña years are assembled as described in the text.

arguments, since they did not have access to a pair of simulations in which only one thing was changed. This motivated us to perform a second run (NODUST), which was identical to DUST, except that the Australian dust source was set to zero.

Comparison of the dust simulation with observations and other models led us to conclude that our dust concentrations and resultant radiative forcing are probably somewhat too large. We attributed this to the treatment of sub-grid wind speed used in the dust emission scheme. However, the spatial pattern of dust over Australia was captured rather well by our model, in which the dust emission scheme assigns enhanced erodibility to topographic depressions (Ginoux et al., 2001).
To investigate possible dust-ENSO-rainfall feedbacks in the model, we focused on the austral spring season (SON), when the correlation between rainfall and ENSO is strongest over Australia. We used ordinary least squares linear regression against Niño3.4-SST to characterise the variation of rainfall, dust and other quantities with respect to ENSO. We found that the ENSO-rainfall relationship over eastern Australia was stronger in the DUST run: dry (El Niño) years tended to be drier, and wet (La Niña) years wetter. The ENSO-rainfall relationship was also weaker over northwestern Australia in the DUST run. The amplification of ENSO-related rainfall variability over eastern Australia and the weaker ENSO-rainfall relationship over the north-west both represented an improvement relative to observations. 


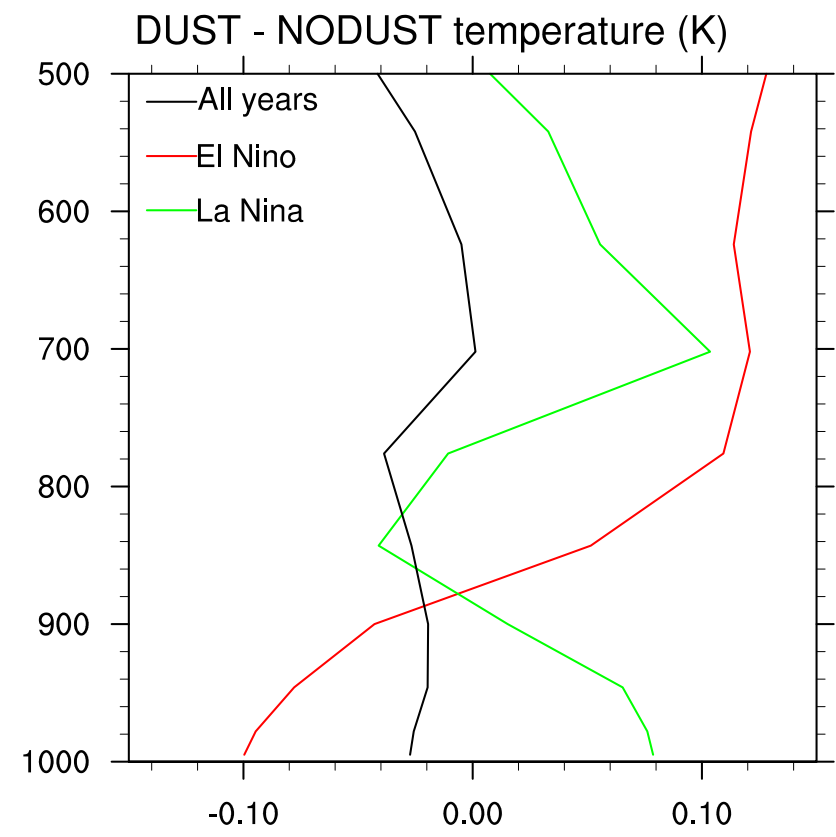

Fig. 15. As Fig. 14, but showing profiles of dust-induced temperature changes (difference between the DUST and NODUST runs). The dust-induced SST change is plotted at $1013 \mathrm{hPa}$.

We showed that the mechanism is related to ENSOinduced anomalies of radiative forcing by Australian dust over the south-west Pacific Ocean, which increase (decrease) surface evaporation in La Niña (El Niño) years. Some of this moisture is advected by the prevailing easterly winds towards eastern Australia, where increased (decreased) moisture convergence in La Niña (El Niño) years increases the amplitude of ENSO-related changes in moist static instability. In turn, this increases the amplitude of ENSO-related rainfall variability. The weaker ENSO-rainfall relationship over the north-west in the DUST run is most likely due to a positive feedback between moisture convergence and rainfall over north-eastern Australia: in essence, more convection and rainfall there depletes the atmosphere of moisture, so less is available for advection towards north-western Australia.

There are some interesting aspects of the dust - radiation - evaporation feedback over the south-western Pacific Ocean in our model: (1) The increased response of evaporation to ENSO in the presence of dust was larger than expected solely from changes in dust radiative forcing at the ocean surface. We showed that the additional effect could be explained by changes in stability between the ocean surface and the boundary layer induced by atmospheric heating by dust. It was enhanced because, below about $800 \mathrm{hPa}$, shortwave and longwave effects were additive (both acting to warm the atmosphere). (2) Dust-induced changes in the lower-tropospheric vertical temperature profile (diagnosed from the difference between the DUST and NODUST runs) were small when all years of simulation were included. How- ever, considering composites of La Niña and El Niño years separately, differences in the temperature profile were qualitatively consistent with ENSO-related anomalies in atmospheric heating by dust. We argued that the ENSO-related forcing anomalies were more important than the mean dust radiative forcing because, on long time scales, atmospheric and oceanic energy transports ensure that the opposing effects of surface cooling and atmospheric heating are well mixed and become relatively small. However, on shorter time scales, dust-induced anomalies in SST and atmospheric stability, such as those related to ENSO, can exert substantial climatic effects. These aspects of the dust - radiation evaporation feedback merit further study. An especially interesting question is whether the greater importance of the variability in the dust forcing, compared to the mean forcing, can be reproduced in other models or in other regions.

There are important uncertainties regarding our conclusions. Comparison with observations suggests that the radiative effects of dust may be over-estimated in our model, so the impact of dust on the simulated rainfall variability may also be exaggerated. On the other hand, the model uses prescribed vegetation, so possible feedbacks due to interannual and interdecadal changes in vegetation properties are not simulated. In principle, these might be expected to enhance the variability of the dust source in response to natural rainfall fluctuations. Another uncertainty concerns the simulation of ENSO itself in the model. In common with most other GCMs, Mk3.6 suffers from the Pacific equatorial cold-tongue bias: the tongue of SST anomalies associated with ENSO extends too far west towards the eastern Indian Ocean, which is expected to generate an ENSO-rainfall relationship that is centred too far west over Australia (e.g., Shi et al., 2008). How this relates to our results should be considered in a future study. More generally, many aspects of our simulation may be sensitive to details of the physics, so it will be important to test our findings with other models.

To our knowledge, this is the first study that has demonstrated a climatic response to the radiative effects of Australian dust. Although the Australian dust source is smaller than the major sources in the Northern Hemisphere, our results show that the direct radiative effects of Australian dust may have important interactions with climate variability. The results suggest that (1) a realistic treatment of Australian dust may be necessary for accurate simulation of the ENSOrainfall relationship over Australia, and (2) radiative feedbacks involving dust may be important for understanding natural rainfall variability over Australia. (1) is potentially important for climate modelling, because ENSO dominates rainfall variability over most of eastern and central Australia, and the response of ENSO to climate change is an active research question (Collins et al., 2010). (2) raises various research questions, e.g., it is possible that there is a positive feedback on drought induced by the recent observed increase in Australian dust (Mitchell et al., 2010). Although our model tends to over-estimate the Australian dust source, it is 
possible that the use of prescribed vegetation causes rainfalldust feedbacks to be under-estimated in some respects. It would be intriguing to explore these effects using a model that includes dynamic vegetation in a future study.

Acknowledgements. This work was funded in part by the Australian Climate Change Science Program (ACCSP). The authors thank Ian Watterson for helpful discussions, and the anonymous reviewers for their constructive comments.

Edited by: C. Hoose

\section{References}

Bullard, J., Baddock, M., McTainsh, G., and Leys, J.: Sub-basin scale dust source geomorphology detected using MODIS, Geophys. Res. Lett., 35, L15404, doi:10.1029/2008GL033928, 2008.

Cakmur, R. V., Miller, R. L., Perlwitz, J., Geogdzhayev, I. V., Ginoux, P., Koch, D., Kohfeld, K. E., Tegen, I., and Zender, C. S.: Constraining the magnitude of the global dust cycle by minimizing the difference between a model and observations, J. Geophys. Res., 111, D6207, doi:10.1029/2005JD005791, 2006.

Chou, M.-D. and Lee, K.-T.: A Parameterization of the Effective Layer Emission for Infrared Radiation Calculations, J. Atmos. Sci., 62, 531-541, 2005.

Collins, M., An, S.-I., Cai, W., Ganachaud, A., Guilyardi, E., Jin, F.-F., Jochum, M., Lengaigne, M., Power, S., Timmermann, A., Vecchi, G., and Wittenberg, A.: The impact of global warming on the tropical Pacific ocean and El Nino, Nat. Geosci., 3, 391397, doi:10.1038/NGEO868, 2010.

Cook, B. I., Miller, R. L., and Seager, R.: Amplification of the North American "Dust Bowl" drought through human-induced land degradation, P. Natl. Acad. Sci. USA, 106, 4997-5001, doi:10.1073/pnas.0810200106, 2009.

Deardorff, J. W.: Convective velocity and temperature scales for the unstable planetary boundary layer and for Rayleigh convection, J. Atmos. Sci., 27, 1211-1213, 1970.

Dubovik, O., Holben, B., Eck, T., Smirnov, A., Kaufman, Y., King, M., Tanre, D., and Slutsker, I.: Variability of absorption and optical properties of key aerosol types observed in worldwide locations, J. Atmos. Sci., 59, 590-608, 2002.

Evan, A. T., Dunion, J., Foley, J. A., Heidinger, A. K., and Velden, C. S.: New evidence for a relationship between Atlantic tropical cyclone activity and African dust outbreaks, Geophys. Res. Lett., 33, L19813, doi:10.1029/2006GL026408, 2006.

Fan, J., Zhang, R., Tao, W., and Mohr, K. I.: Effects of aerosol optical properties on deep convective clouds and radiative forcing, J. Geophys. Res., 113, D8209, doi:10.1029/2007JD009257, 2008.

Fécan, F., Marticorena, B., and Bergametti, G.: Parametrization of the Increase of the Aeolian Erosion Threshold Wind Friction Velocity Due to Soil Moisture for Arid and Semi-Arid Areas, Ann. Geophysicae, 17, 149-157, 1999.

Gillette, D. A. and Passi, R.: Modeling dust emission caused by wind erosion, J. Geophys. Res., 93, 14233-14242, 1988.

Ginoux, P., Chin, M., Tegen, I., Prospero, J. M., Holben, B., Dubovik, O., and Lin, S.-J.: Sources and distributions of dust aerosols simulated with the GOCART model, J. Geophys. Res., 106, 20255-20273, doi:10.1029/2000JD000053, 2001.
Ginoux, P., Prospero, J. M., Torres, O., and Chin, M.: Long-term simulation of global dust distribution with the GOCART model: correlation with North Atlantic Oscillation, Environ. Modell. Softw., 19, 113-128, 2004.

Gordon, H. B., O'Farrell, S. P., Collier, M. A., Dix, M. R., Rotstayn, L. D., Kowalczyk, E. A., Hirst, A. C., and Watterson, I. G.: The CSIRO Mk3.5 Climate Model, Technical Report No. 21, The Centre for Australian Weather and Climate Research, Aspendale, Vic., Australia, 62 pp, available at: http://www.cawcr. gov.au/publications/technicalreports.php, 2010.

Grant, K. E., Chuang, C. C., Grossman, A. S., and Penner, J. E.: Modeling the spectral optical properties of ammonium sulfate and biomass burning aerosols: parameterization of relative humidity effects and model results, Atmos. Environ., 33, 26032620, 1999.

Gregory, D. and Rowntree, P. R.: A mass flux convection scheme with representation of cloud ensemble characteristics and stability-dependent closure, Mon. Weather Rev., 118, 14831506, 1990.

Grini, A., Tulet, P., and Gomes, L.: Dusty weather forecasts using the MesoNH mesoscale atmospheric model, J. Geophys. Res., D19205, doi:10.1029/2005JD007007, 2006.

Haywood, J., Francis, P., Osborne, S., Glew, M., Loeb, N., Highwood, E., Tanré, D., Myhre, G., Formenti, P., and Hirst, E.: Radiative properties and direct radiative effect of Saharan dust measured by the C-130 aircraft during SHADE: 1 . Solar spectrum, J. Geophys. Res., 108, 8577, doi:10.1029/2002JD002687, 2003.

Hess, M., Koepke, P., and Schult, I.: Optical properties of aerosols and clouds: The software package OPAC, B. Am. Meteorol. Soc., 79, 831-844, 1998.

Highwood, E. J., Haywood, J. M., Silverstone, M. D., Newman, S. M., and Taylor, J. P.: Radiative properties and direct effect of Saharan dust measured by the C-130 aircraft during Saharan Dust Experiment (SHADE): 2. Terrestrial spectrum, J. Geophys. Res., 108, 8578, doi:10.1029/2002JD002552, 2003.

Holtslag, A. A. M. and Boville, B. A.: Local versus non-local boundary layer diffusion in a global climate model, J. Climate, 6, 1825-1842, 1993.

Ishizuka, M., Mikami, M., Leys, J., Yamada, Y., Heidenreich, S., Shao, Y., and McTainsh, G. H.: Effects of soil moisture and dried raindroplet crust on saltation and dust emission, J. Geophys. Res., 113, D24212, doi:10.1029/2008JD009955, 2008.

Ito, A. and Penner, J. E.: Global estimates of biomass burning emissions based on satellite imagery for the year 2000, J. Geophys. Res., 109, D14S05, doi:10.1029/2003JD004423, 2004.

Ito, A. and Penner, J. E.: Historical emissions of carbonaceous aerosols from biomass and fossil fuel burning for the period 1870-2000, Glob. Biogeochem. Cyc., 19, GB2028, doi:10.1029/2004GB002374, 2005.

Jiang, H. and Feingold, G.: Effect of aerosol on warm convective clouds: Aerosol-cloud-surface flux feedbacks in a new coupled large eddy model, J. Geophys. Res., 111, D01202, doi:10.1029/2005JD006138, 2006.

Jones, D. A., Wang, W., and Fawcett, R.: High-quality spatial climate data-sets for Australia, Aust. Meteorol. Oceanogr. J., 58, 233-248, 2009.

Lau, K. M., Kim, K. M., Sud, Y. C., and Walker, G. K.: A GCM study of the response of the atmospheric water cycle of West Africa and the Atlantic to Saharan dust radiative forcing, 
Ann. Geophys., 27, 4023-4037, doi:10.5194/angeo-27-40232009, 2009.

Liao, H. and Seinfeld, J. H.: Effect of clouds on direct aerosol radiative forcing of climate, J. Geophys. Res., 103, 3781-3788, 1998.

Liepert, B. G., Feichter, J., Lohmann, U., and Roeckner, E.: Can aerosols spin down the water cycle in a warmer and moister world?, Geophys. Res. Lett., 31, L06207, doi:10.1029/2003GL019060, 2004.

Louis, J.-F.: A Parametric Model of Vertical Eddy Fluxes in the Atmosphere, Bound. Lay. Meteorol., 17, 187-202, 1979.

Lunt, D. J. and Valdes, P. J.: The modern dust cycle: Comparison of model results with observations and study of sensitivities, J. Geophys. Res., 107, 4669, doi:10.1029/2002JD002316, 2002.

Mackie, D. S., Boyd, P. W., McTainsh, G. H., Tindale, N. W., Westberry, T. K., and Hunter, K. A.: Biogeochemistry of iron in Australian dust: From eolian uplift to marine uptake, Geochem. Geophys. Geosyst., 9, Q03Q08, doi:10.1029/2007GC001813, 2008.

McBride, J. L. and Nicholls, N.: Seasonal relationships between Australian rainfall and the Southern Oscillation, Mon. Weather Rev., 111, 1998-2004, 1983.

McGregor, J. L.: Economical Determination of Departure Points for Semi-Lagrangian Models, Mon. Weather Rev., 121, 221-230, 1993.

McTainsh, G. H., Leys, J. F., and Nickling, W.: Wind erodibility of arid lands in the channel country of western Queensland, Australia, Z. Geomorphol., 116, 113-130, 1999.

McTainsh, G. H., Tews, E. K., Leys, J. F., and Bastin, G.: Spatial and temporal trends in wind erosion of Australian rangelands during 1960 to 2005 using the Dust Storm Index (DSI), Report for the Australian Collaborative Rangeland Information System [ACRIS], available at: http://www.environment.gov.au/ land/publications/acris/wind-erosion.html, 2007.

Miller, R. L., Tegen, I., and Perlwitz, J.: Surface radiative forcing by soil dust aerosols and the hydrologic cycle, J. Geophys. Res., 109, D04203, doi:10.1029/2003JD004085, 2004.

Miller, R. L., Cakmur, R. V., Perlwitz, J., Geogdzhayev, I. V., Ginoux, P., Koch, D., Kohfeld, K. E., Prigent, C., Ruedy, R., Schmidt, G. A., and Tegen, I.: Mineral dust aerosols in the NASA goddard institute for Space Sciences ModelE atmospheric general circulation model, J. Geophys. Res., 111, D06208, doi:10.1029/2005JD005796, 2006.

Mitchell, R. M. and Campbell, S. K.: The Australian Aerosol Ground Station Network: Status Report and Development of a Radiometric Calibration Facility, Optica Pura y Aplicada, 37, 3259-3262, 2004.

Mitchell, R. M., Campbell, S. K., and Qin, Y.: Recent increase in aerosol loading over the Australian arid zone, Atmos. Chem. Phys., 10, 1689-1699, doi:10.5194/acp-10-1689-2010, 2010.

Myhre, G., Grini, A., Haywood, J. M., Stordal, F., Chatenet, B., Tanré, D., Sundet, J. K., and Isaksen, I. S. A.: Modeling the radiative impact of mineral dust during the Saharan Dust Experiment (SHADE) campaign, J. Geophys. Res., 108, 8579, doi:10.1029/2002JD002566, 2003.

Penner, J. E., Zhang, S. Y., and Chuang, C. C.: Soot and smoke aerosol may not warm climate, J. Geophys. Res., 108, 4657, doi:10.1029/2003JD003409, 2003.

Perlwitz, J. and Miller, R. L.: Cloud cover increase with increasing aerosol absorptivity: A counterexample to the conventional semidirect aerosol effect, J. Geophys. Res., 115, D08203,
doi:10.1029/2009JD012637, 2010.

Prospero, J. M. and Lamb, P. J.: African Droughts and Dust Transport to the Caribbean: Climate Change Implications, Science, 302, 1024-1027, doi:10.1126/science.1089915, 2003.

Prospero, J. M., Ginoux, P., Torres, O., Nicholson, S. E., and Gill, T. E.: Environmental characterization of global sources of atmospheric soil dust identified with the NIMBUS 7 Total Ozone Mapping Spectrometer (TOMS) absorbing aerosol product, Rev. Geophys., 40, 1002, doi:10.1029/2000RG000095, 2002.

Qin, Y. and Mitchell, R. M.: Characterisation of episodic aerosol types over the Australian continent, Atmos. Chem. Phys., 9, 1943-1956, doi:10.5194/acp-9-1943-2009, 2009.

Ramanathan, V., Crutzen, P. J., Kiehl, J. T., and Rosenfeld, D.: Aerosols, climate and the hydrological cycle, Science, 294, 2119-2124, 2001.

Rayner, N. A., Parker, D. E., Horton, E. B., Folland, C. K., Alexander, L. V., Rowell, D. P., Kent, E. C., and Kaplan, A.: Globally complete analyses of sea surface temperature, sea ice and night marine air temperature, J. Geophys. Res., 108, 4407, doi:10.1029/2002JD002670, 2003.

Redelsperger, J.-L., Guichard, F., and Mondon, S.: A Parameterization of Mesoscale Enhancement of Surface Fluxes for LargeScale Models, J. Climate, 13, 402-421, 2000.

Ridgwell, A. J.: Dust in the Earth system: the biogeochemical linking of land, air and sea, Philos. Trans. R. Soc. Lond. Ser. A-Math. Phys. Eng. Sci., 360, 2905-2924, doi:10.1098/rsta.2002.1096, 2002.

Roderick, M. L. and Farquhar, G. D.: The cause of decreased pan evaporation over the past 50 years, Science, 298, 1410-1411, 2002.

Ropelewski, C. F. and Halpert, M. S.: Global and regional scale precipitation associated with El Niño/Southern Oscillation, Mon. Weather Rev., 115, 1606-1626, 1987.

Rosenfeld, D., Rudich, Y., and Lahav, R.: Desert dust suppressing precipitation: a possible desertification feedback loop, P. Natl. Acad. Sci. USA, 98, 5975-5980, 2001.

Rotstayn, L. D. and Lohmann, U.: Simulation of the tropospheric sulfur cycle in a global model with a physically based cloud scheme, J. Geophys. Res., 107, 4592, doi:10.1029/2002JD002128, 2002.

Rotstayn, L. D., Cai, W., Dix, M. R., Farquhar, G. D., Feng, Y., Ginoux, P., Herzog, M., Ito, A., Penner, J. E., Roderick, M. L., and Wang, M.: Have Australian Rainfall and Cloudiness Increased Due to the Remote Effects of Asian Anthropogenic Aerosols?, J. Geophys. Res., 112, D09202, doi:10.1029/2006JD007712, 2007.

Rotstayn, L. D., Collier, M. A., Feng, Y., Gordon, H. B., O'Farrell, S. P., Smith, I. N., and Syktus, J.: Improved simulation of Australian climate and ENSO-related rainfall variability in a GCM with an interactive aerosol treatment, Int. J. Climatol., 30, 10671088, doi:10.1002/joc.1952, 2010.

Satheesh, S. K. and Moorthy, K. K.: Radiative effects of natural aerosols: A review, Atmos. Environ., 39, 2089-2110, 2005.

Sato, M., Hansen, J. E., McCormick, M. P., and Pollack, J. B.: Stratospheric aerosol optical depth, 1850-1990, J. Geophys. Res., 98, 22987-22994, 1993.

Shi, G., Cai, W., Cowan, T., Ribbe, J., Rotstayn, L., and Dix, M.: Variability and trend of the northwest Western Australia Rainfall: observations and coupled climate modeling, J. Climate, 21, 2938-2959, 2008. 
Smith, I. N.: Global climate modelling within CSIRO: 1981 to 2006, Aust. Meteorol. Mag., 56, 153-166, 2007.

Solmon, F., Mallet, M., Elguindi, N., Giorgi, F., Zakey, A., and Konaré, A.: Dust aerosol impact on regional precipitation over western Africa, mechanisms and sensitivity to absorption properties, Geophys. Res. Lett., 35, L24705, doi:10.1029/2008GL035900, 2008.

Stephens, G. L., Wood, N. B., and Pakula, L. A.: On the radiative effects of dust on tropical convection, Geophys. Res. Lett., 31, L23112, doi:10.1029/2004GL021342, 2004.

Sun, D., Lau, W. K. M., Kafatos, M., Boybeyi, Z., Leptoukh, G., Yang, C., and Yang, R.: Numerical Simulations of the Impacts of the Saharan Air Layer on Atlantic Tropical Cyclone Development, J. Climate, 22, doi:10.1175/2009JCLI2738.1, 2009.

Tanaka, T. Y. and Chiba, M.: A numerical study of the contributions of dust source regions to the global dust budget, Glob. Planet. Change, 52, 88-104, doi:10.1016/j.gloplacha.2006.02.002, 2006.

Tegen, I., Harrison, S. P., Kohfeld, K., Prentice, I. C., Coe, M., and Heimann, M.: Impact of vegetation and preferential source areas on global dust aerosol: Results from a model study, J. Geophys. Res., 107, 4576, doi:10.1029/2001JD000963, 2002.

van den Dool, H. M., Saha, S., and Johansson, A.: Empirical orthogonal teleconnections, J. Climate, 13, 1421-1435, 2000.

Van Leer, B.: Towards the Ultimate Conservative Difference Scheme. V. A New Approach to Numerical Convection, J. Comp. Phys., 23, 276-299, 1977.

Washington, R., Todd, M. C., Engelstaedter, S., Mbainayel, S., and Mitchell, F.: Dust and the low-level circulation over the Bodélé Depression, Chad: Observations from BoDEx 2005, J. Geophys. Res., 111, D3201, doi:10.1029/2005JD006502, 2006.

Washington, R., Todd, M., Middleton, N. J., and Goudie, A. S.: Dust-storm source areas determined by the total ozone monitoring spectrometer and surface observations, Ann. Ass. Am. Geogr., 93, 297-313, 2003.

Watterson, I. G.: Non-dimensional measures of climate model performance, Int. J. Climatol., 16, 379-391, 1996.

Watterson, I. G.: An analysis of the global water cycle of present and doubled $\mathrm{CO}_{2}$ climates simulated by the CSIRO general circulation model, J. Geophys. Res., 103, 23113-23130, doi:10.1029/98JD02022, 1998.
Webb, N. P., McGowan, H. A., Phinn, S. R., and McTainsh, G. H.: AUSLEM (AUStralian Land Erodibility Model): A tool for identifying wind erosion hazard in Australia, Geomorphology, 78, 179-200, doi:10.1016/j.geomorph.2006.01.012, 2006.

Wendisch, M., Hellmuth, O., Ansmann, A., Heintzenberg, J., Engelmann, R., Althausen, D., Eichler, H., Wueller, D., Hu, M., Zhang, Y., and Mao, J.: Radiative and dynamic effects of absorbing aerosol particles over the Pearl River Delta, China, Atmos. Environ., 42, 6405-6416, doi:10.1016/j.atmosenv.2008.02.033, 2008.

Woodward, S.: Modeling the atmospheric life cycle and radiative impact of mineral dust in the Hadley Centre climate model, J. Geophys. Res., 106, 18155-18166, 2001.

Wurzler, S., Reisin, T. G., and Levin, Z.: Modification of mineral dust particles by cloud processing and subsequent effects on drop size, J. Geophys. Res., 105, 4501-4512, 2000.

Yoshioka, M., Mahowald, N. M., Conley, A. J., Collins, W. D., Fillmore, D. W., Zender, C. S., and Coleman, D. B.: Impact of Desert Dust Radiative Forcing on Sahel Precipitation: Relative Importance of Dust Compared to Sea Surface Temperature Variations, Vegetation Changes, and Greenhouse Gas Warming, J. Climate, 20, 1445-1467, doi:10.1175/JCLI4056.1, 2007.

Yu, H., Dickinson, R. E., Chin, M., Kaufman, Y. J., Zhou, M., Zhou, L., Tian, Y., Dubovik, O., and Holben, B. N.: Direct radiative effect of aerosols as determined from a combination of MODIS retrievals and GOCART simulations, J. Geophys. Res., 109, D03206, doi:10.1029/2003JD003914, 2004.

Yue, X., Wang, H., Liao, H., and Fan, K.: Simulation of dust aerosol radiative feedback using the GMOD: 2. Dust-climate interactions, J. Geophys. Res., 115, D4201, doi:10.1029/2009JD012063, 2010.

Zar, J. H.: Biostatistical Analysis, 3rd Edition, Prentice Hall International, London, 929 pp, 1996.

Zender, C. S. and Kwon, E. Y.: Regional contrasts in dust emission responses to climate, J. Geophys. Res., 110, D13201, doi:10.1029/2004JD005501, 2005.

Zender, C. S., Newman, D., and Torres, O.: Spatial heterogeneity in aeolian erodibility: Uniform, topographic, geomorphic, and hydrologic hypotheses, J. Geophys. Res., 108, doi:10.1029/2002JD003039, 2003.

Zender, C. S., Miller, R. L., and Tegen, I.: Quantifying mineral dust mass budgets: terminology, constraints, and current estimates, Eos, 85, 509-512, doi:10.1029/2004EO480002, 2004. 